\title{
The Regulation of Synaptogenesis during Normal Development and Following Activity Blockade
}

\author{
Lisa M. Dahmª and Lynn T. Landmesser \\ Department of Physiology and Neurobiology, The University of Connecticut, Storrs, Connecticut 06269
}

The mature neuromuscular junction is characterized by the tight spatial colocalization of synaptic vesicles and acetylcholine receptor (AChR) clusters. Although a large body of work exists on the interactions between motoneurons and myotubes leading to synaptogenesis in tissue culture, how the neuromuscular junction acquires its highly specialized structure in vivo is not well understood, particularly during the earliest period of synaptogenesis. In this study, the development of the neuromuscular synapse in chick hindlimb muscles was examined and quantified by simultaneously labeling the pre- and postsynaptic elements from the time the main nerve trunks leave the lumbosacral plexus region to enter the developing limb (St 24) through the end of the motoneuron cell death period (St 36). Based on these results, synaptogenesis can be divided into several distinct stages that are intimately connected to the innervation sequence described in a previous paper (Dah'm and Landmesser, 1988). Briefly, as large nerve trunks approach the developing muscles and the first AChR clusters are induced to form on nearby myotubes, none of these initial receptor clusters are in direct contact with a nerve profile. The first appearance of nerve-contacted clusters (synapses) is coincident with the growth of large, unbranched nerve trunks into the muscles. The next step is initiated by the formation of small nerve side branches that grow out from the larger intramuscular nerve trunks to bring most axons and myotubes into contact for the first time. As side branches form, synapses appear around them, and non-nerve-contacted receptor clusters disappear from around the main intramuscular nerve trunks. The next step in synaptogenesis is the restriction of synaptic vesicle antigen to sites of synaptic contact. These early stages of synaptogenesis are also characterized by the growth of the presynaptic terminal to match the length of the postsynaptic receptor cluster. This study showed that AChR cluster formation during early in vivo neuromuscular development does not require close anatomical nerve contact, but that the presence of the nerves is necessary for

\footnotetext{
Received May 31, 1990; revised Sep. 4, 1990; accepted Sep. 7, 1990.

We thank Liviu Cupceancu for his technical assistance; Chauney Bowers, Jon Covault, Barbara Fredette, and Guillermo Pilar for helpful comments on the experiments and manuscript; and Jon Covault and Kathy Buckley for R-BTX and the SV2 antibody, respectively, which were essential to the successful completion of the study. This work was supported by NIH Grant NS 19640 and a University of Connecticut Predoctoral Fellowship to Lisa Dahm.

Correspondence should be addressed to Lynn T. Landmesser, The University of Connecticut, Department of Physiology and Neurobiology, 75 N. Eagleville Road, Storrs, CT 06269.

Present address: Division of Biology, California Institute of Technology, Pasadena, CA 91125.
}

Copyright (C) 1991 Society for Neuroscience $0270-6474 / 91 / 010238-18 \$ 03.00 / 0$
AChR clusters to form. This suggests that the nerves normally induce AChR clustering via the release of a diffusible substance, a suggestion substantiated by the observation that AChR clusters do not form on aneural myotubes in vivo. In order to assess the role of synapse formation in the regulation of motoneuron number, synaptogenesis was quantitatively examined after chronic neuromuscular blockade, which prevents motoneuron cell death. Activity blockade caused a large increase in the number of synapses in treated muscles, and the increase in the peak rate of synapse formation occurred prior to the onset of normal motoneuron cell death. This suggests a critical role for synapse formation in the regulation of motoneuron number during development.

During vertebrate neuromuscular development motoneuron axons exit the spinal cord and follow precise pathways to synapse with their target muscles (Landmesser and Morris, 1975; LanceJones and Landmesser, 1981; Hollyday, 1983; Tosney and Landmesser, 1985). Though questions concerning the specificity and precision of motoneuron pathfinding have been well addressed in the intact embryo, those concerning the early events of synaptogenesis have been more difficult to assess in the complex in vivo environment. Thus, most of the information about how the neuromuscular junction acquires its highly specialized structure is derived from observations of motoneurons and myotubes interacting in tissue culture (for reviews, see Dennis et al., 1981; Schuetze and Role, 1987). This is especially true for the earliest events in this process. For instance, though myotubes developing in vitro in the absence of nerves exhibit some AChR clusters on their surfaces (Fischbach and Cohen, 1973; Anderson and Cohen, 1977), cocultured motoneurons do not preferentially innervate these regions of high receptor density. Instead, the motoneuron induces a new aggregate to form at the site of contact (Frank and Fischbach, 1977; Anderson and Cohen, 1977). It is not known to what extent these observations generally reflect the events that occur during development in vivo.

To examine the early events of synaptogenesis in the embryo, it is necessary to visualize the temporospatial relationship between the ingrowing axons, the developing myotubes, and the formation of AChR clusters. Many in vivo studies have examined only one-half of the synapse, i.e., the ingrowing nerves (Letinsky and Morrison-Graham, 1980; Dahm and Landmesser, 1988; Linden and Letinsky, 1988) or the developing AChR clusters (Bevan and Steinbach, 1977; Burden, 1977a,b; Steinbach, 1981; Phillips et al., 1985). Others have focused on later events in the development of the NMJ (Jacob and Lentz, 1979) or on different aspects of the development of the NMJ, such as the time course of functional innervation (Landmesser and Mor- 
ris, 1975; Dennis, 1981; Ziskind-Conhaim and Bennett, 1982) or the incidence of close erve terminal apposition to AChR clusters visualized at the electron microscopic level (Smith and Slater, 1983). Although more recent papers have described the initial appearance of AChR clusters in avian muscles (Godfrey et al., 1988; Fallon and Gelfman, 1989) and noted the gross timing of cluster formation with respect to innervation, there has been no quantitative analysis of the overall temporospatial relationship between the ingrowing axons and the formation of AChR clusters during the initial stages of neuromuscular development in vivo. Furthermore, despite a growing body of information that correlates neuromuscular function with NMJ structure in vitro (Peng et al., 1979; Weldon and Cohen, 1979; Nakajima et al., 1980; Takahashi et al., 1987; Buchanan et al., 1989), much less is known about the structure of the earliest functional synapses in the embryo.

Another important reason to study synaptogenesis in vivo is the potential role of synapse formation in the regulation of naturally occurring motoneuron cell death (for reviews, see Cunningham, 1982; Hamburger and Oppenheim, 1982; Lamb, 1984; Pilar et al., 1988). We previously demonstrated that intramuscular nerve ingrowth and branching were highly stereotyped and precisely rcgulatcd for several chick muscles, bringing most myotubes into contact with nerve branches by the middle of the motoneuron cell death period (Dahm and Landmesser, 1988). In addition, chronic blockade of neuromuscular activity with d-Tubocurarine (dTC) or $\alpha$-bungarotoxin rescues motoneurons from cell death (Pittman and Oppenheim, 1978, 1979) and also causes a large increase in intramuscular nerve branching (Dahm and Landmesser, 1988). These results are consistent with the possibility that these branches represent sites of uptake of muscle-derived trophic factor and that the increase in branches following activity blockade would result in enhanced motoneuron survival by allowing greater uptake of trophic factor. Since initial observations indicated that the side branches were also the sites of synapse formation in the muscles (Dahm and Landmesser, 1988), one possibility is that synaptic contact is necessary for trophic factor uptake. Therefore, in this paper, the course of synaptogenesis is examined quantitatively from the timc that the major nerve trunks leave the plexus region to enter the limb (St 24) through the end of the cell death period (St 37) both during normal development and following treatment with dTC to prevent cell death.

\section{Materials and Methods}

White Leghorn chick embryos were incubated in a humidified, forceddraft incubator at $38^{\circ} \mathrm{C}$ until the desired age, staged according to Hamburger and Hamilton (1951) and subjected to the following procedures.

\section{Muscle whole-mounts}

Muscle whole-mounts were prepared as previously described (Dahm and Landmesser, 1988). Briefly, embryos were decapitated, eviscerated, and placed in oxygenated Tyrodes at room temperature $\left(20-23^{\circ} \mathrm{C}\right)$. Skin and connective tissue were removed to reveal the underlying muscles. The iliofibularis (IFIB) and posterior iliotibialis (PITIB) muscles were carefully stripped of all connective tissue and the sciatic trunk was removed from the ventral surface of the IFIB. The muscles were left attached to the limb during all staining procedures.

Two different antibodies were used to visualize the axons in wholemounts: C-2, a mouse IgG monoclonal antibody against a neuronal cytoskeletal element (Dahm and Landmesser, 1988) and SV2, a mouse IgG monoclonal that recognizes a synaptic vesicle antigen (Buckley and Kelly, 1985). To confirm that our results were independent of the expression of a particular antigen, nerves were also visualized with DiI, a lipid soluble fluorescent dye that labels both axons and growth cones
(Honig and Hume, 1986), as well as by anterogradely transported horseradish peroxidase (HRP).

For C-2 immunostaining, muscles were fixed in cold acetone for 2 min, washed in phosphate-buffered saline (PBS) (all washes were for 15-20 min with 3 changes), incubated in primary antibody (undiluted hybridoma supernatant) containing $0.3 \%$ Triton for $1-3 \mathrm{hr}$ at room temperature, washed in PBS, fixed in $3.7 \%$ formaldehyde-PBS for $15-$ 30 min, washed in PBS, incubated in rhodamine isothiocyanate (RITC)labeled secondary antibody for $1 \mathrm{hr}$ at room temperature or overnight at $4^{\circ} \mathrm{C}$, and washed in PBS. For SV2 immunostaining, muscles were fixed in $3.7 \%$ formaldehyde-PBS for $15-30 \mathrm{~min}$, washed in PBS, incubated in primary antibody (1:100 dilution of hybridoma supernatant) containing $0.3 \%$ Triton for $2-3 \mathrm{hr}$ at room temperature or overnight at $4^{\circ} \mathrm{C}$, washed in PBS, incubated in fluorescein isothiocyanate (FITC)labeled secondary antibody for $1 \mathrm{hr}$ at room temperature or overnight at $4^{\circ} \mathrm{C}$, and washed in PBS.

Muscles were labeled in one of 2 ways to visualize synapses: (1) The limbs were fixed in 3.7\% formaldehyde-PBS for 30-60 min, washed in PBS, incubated in SV2 (1:100 dilution of the hybridoma supernatant containing $0.3 \%$ Triton) for $2-3 \mathrm{hr}$ at room temperature or overnight at $4^{\circ} \mathrm{C}$, washed in PBS, incubated in RITC-goat-anti-mouse IgG for $1-$ $2 \mathrm{hr}$ at room temperature or overnight at $4^{\circ} \mathrm{C}$, washed in PBS, incubated for $30 \mathrm{~min}$ in $10 \%$ Rat Serum-PBS, then incubated for $2-3 \mathrm{hr}$ at room temperature or overnight at $4^{\circ} \mathrm{C}$ in MAb35 (Tzartos and Lindstrom, 1980), a rat IgG monoclonal that recognizes the $\alpha$-subunit of the AChR, to which FITC had been directly conjugated (1:50 dilution; see below for conjugation procedure), washed in PBS and mounted as above. (2) Limbs were fixed as in (1), washed in PBS, incubated in R-BTX (25 $\mathrm{nM}$ ) for $2 \mathrm{hr}$ at room temperature, washed in PBS, incubated in SV2 as above, washed in PBS, incubated in FITC-goat-anti-mouse IgG for 2 $\mathrm{hr}$ at room temperature, washed in PBS and mounted as above.

\section{Preparation of dye-conjugated MAb35}

Prior to conjugation with FITC, MAb35-IgG was partially purified by ion-exchange chromatography (Baker $\mathrm{AbX}$ ) according to the manufacturer's instructions. This procedure resulted in approximately $90 \%$ pure IgG. FITC was conjugated to MAb35 using a previously published procedure (Anderson and Fambrough, 1983). Briefly, $12 \mathrm{mg} \mathrm{FITC/mg}$ $\mathrm{IgG}$ were added at 20 -min intervals to the antibody with constant stirring at room temperature. After $3 \mathrm{hr}$, the reaction mixture was concentrated to $1 \mathrm{ml}$ and the labeled antibody isolated by gel filtration on Biogel-P-2 (Bio-Rad Laboratories, Richmond, CA). The FITC-MAb35 conjugate was divided into $50 \mu \mathrm{l}$ aliquots and stored at $-20^{\circ} \mathrm{C}$ until needed.

\section{Frozen sections}

Embryos were fixed in $3.7 \%$ formaldehyde-PBS for $1 \mathrm{hr}$, washed in PBS, infiltrated in $30 \%$ sucrose-PBS, mounted in OCT (Tissue Tek) embedding medium, and frozen quickly in a dry ice/methylbutane mixture. Fifteen-micrometer-thick cross sections of the thigh were taken from the limb and processed for immunohistochemistry. In order to visualize the pre- and postsynaptic elements within the same section, dried sections were rinsed in PBS to remove the OCT and then stained using 1 of the following protocols: (1) sections were incubated in SV2 for $1 \mathrm{hr}$, washed in PBS, incubated in RITC-labeled secondary antibody for 30 min, washed in PBS, incubated in 10\% Rat Serum-PBS for 10-15 min, incubated in MAb35-FITC for $2 \mathrm{hr}$, washed in PBS, and mounted in $50 \%$ glycerin-PBS containing $0.03 \mathrm{mg} / \mathrm{ml}$-phenylenediamine (Sigma) to inhibit fading; (2) sections were incubated in R-BTX for $2 \mathrm{hr}$, washed in PBS, incubated in SV2 for $1 \mathrm{hr}$, washed in PBS, incubated in FITClabeled secondary antibody for $\mathbf{3 0} \mathrm{min}$, washed in PBS and mounted in glycerin as above. In some cases, adjacent sections were stained with MAb35 followed by rabbit-anti-rat-IgG (no fluorophore) and then antirabbit-IgG-FITC in order to enhance the fluorescent signal.

FITC- and RITC-goat-anti-mouse IgG, FITC- and RITC-goat-antirabbit IgG, and rabbit-anti-rat IgG were obtained from Sigma (St. Louis, MO). All secondary antibodies were diluted 1:50-1:100. The MAb35 secreting hybridoma cell line was obtained from American Type Tissue Culture Collection. R-BTX and the SV2 antibody were generous gifts of Jon Covault and Kathleen Buckley, respectively.

\section{Drug treatments}

For the series of embryos in which motility was chronically blocked, a square hole was made in the eggshell and a window fashioned from a 
coverslip was sealed in place with melted paraffin. Embryos were given $2 \mathrm{mg}$ of d-Tubocurarine (dTC, Sigma) in $0.1 \mathrm{ml}$ of sterile saline via daily application to the chorioallantoic membrane from St 28-37 (Day 5.5-11); 42 such embryos were used in this study. The hindlimbs were processed for whole-mounts or for frozen sections. To confirm that this dose of dTC blocked motility, the number of hindlimb movements during a 3-min observation period was counted each day. The decrease in motility was similar to that described earlier (see Oppenheim, 1975), therefore motility counts are not reported here.

\section{Neural tube removals}

Neural tubes were removed from St 16-18 embryos according to previously published procedures (Landmesser and Honig, 1986). Briefly a square hole was made in the eggshell and cuts made through the membranes to reveal the underlying embryo. A sharp tungsten needle was used to bisect the neural tube from the midthoracic region caudally to the tail. The neural tube was then carefully removed with a broken off micropipette using suction. A coverslip was then sealed in place with melted paraffin and embryos were incubated until the desired stage. In order to assess the completeness of the spinal cord deletion, ventral laminectomies were performed on operated embryos and the lumbosacral region was inspected visually to determine the extent of spinal cord deletion. In addition, for those embryos in which synapses were quantified from serial frozen sections, adjacent sections were labeled to visualize the nerves. In these embryos no intramuscular nerves were observed in either the IFIB or the PITIB muscles.

\section{Quantification of synapses}

For the purposes of this study, a synapse was defined as the colocalization of a presynaptic profile labeled with SV2 and an acetylcholine receptor (AChR) cluster labeled with FITC-MAb35 or R-BTX. For optimal visualization of synapses, R-BTX was better than FITC-MAb35. The C-2 antibody was not useful for the purpose of quantifying synapse formation since it did not appear to label the presynaptic nerve terminal (L. M. Dahm, unpublished observations). The temporal course of synapse formation was determined by quantifying the percentage of AChR clusters that were colocalized with an SV2-labeled profile in doublelabeled muscle whole-mounts during the cell death period. An AChR cluster was considered to be colocalized if it was contacted at any point along its length by a labeled nerve profile. For each muscle, all of the AChR clusters within 10-15 randomly selected fields were observed and classified as colocalized or not, until a total of 100 clusters were observed. In addition, both the total number of synapses and the total number of AChR clusters were counted in the PITIB muscle at St 30 , 33 , and 36 from every 4 th, 5 th, or 20 th frozen section, respectively. Data were obtained in this way for both control and dTC-treated muscles. AChR clusters and synapses were counted directly under microscopic visualization (Nikon Microphot at $400 \times$ magnification).

When quantifying the total number of synapses in an entire muscle, errors could have resulted from counting the same synapse in each of 2 sections. To determine to what extent corrections for overcounting were required, the lengths of the postsynaptic AChR clusters were measured from projected negatives of muscle whole-mounts at St 31 and St 37 for control and treated muscles. The mean length of the ACh receptor cluster did not differ significantly between control and dTCtreated muscles at St 31 (7.4 and $8.6 \mu \mathrm{m}$, respectively) or at St $37(10.8$ and $10.2 \mu \mathrm{m}$, respectively), though there was a slight increase in length between the 2 stages. Thus, when comparing total numbers of receptor clusters in dTC-treated and control muscles, any correction for overcounting would have affected both proportionately.

In contrast, the proportion of the AChR cluster actually occupied by the presynaptic profile was observed to differ between muscle wholemounts of the 2 groups (see Table 3). For example, at St 31 the presynaptic terminal occupied more than half of the receptor cluster in only $17 \%$ of the synapses in control muscles, whereas this value was $35 \%$ for the dTC-treated muscles. Thus, it was possible that this increase in the length of the "synapse" following dTC treatment would have resulted in an overestimate of synapses when comparing the dTC-treated muscles to the controls. To see to what extent the increase in synapses we observed $(3.3 \times)$ could be explained by this, we considered the worst case situation: assuming that all the dTC-treated synapses occupied $100 \%$ of the cluster, whereas all the control synapses were half this length, one obtains values of $3.7 \mu \mathrm{m}$ and $8.6 \mu \mathrm{m}$ for synaptic length of control and dTC-trealed muscles, respectively, at St 31. Given the sec- tion thickness and the correction factor of Abercrombie (1946), the corrected mean number of synapses at St 31 was 1783 for control and 4394 for dTC-treated muscles. Thus d $\mathrm{TC}$ treatment resulted in a $2.5 \times$ increase in synapses even with this correction. At St 37, the modest increase observed in the number of synapses, 28,337 vs. 20,783 , or a ratio of 1.4 , was reduced to a ratio of only 1.1 following application of this same correction factor $(16,867$ vs. 15,282$)$.

In order to determine when AChR clusters and synapses first appeared during normal development, observations were also made from serial frozen sections of muscles from St 24-29 for both the IFIB and the PITIB. At these stages counts were made from every other section ( $\mathrm{St}$ 24 and 25 ) or from every third section (St 27-29). Finally, both muscles were also examined at $\mathrm{St} 28$ following $12 \mathrm{hr}$ of curare treatment and at St 29 following $24 \mathrm{hr}$ of curare treatment to determine the earliest effects of activity blockade (counts were from every third section at both stages).

\section{Electron microscopy}

Embryos were decapitated, eviscerated, and placed in an oxygenated Tyrodes bath at room temperature $\left(20-23^{\circ} \mathrm{C}\right)$. Skin, connective tissue, and all of the thigh muscles except the IFIB and PITIB were removed from both hindlimbs; the sciatic nerve trunk was left intact, since the points of emergence of the muscle nerves were used as landmarks for making sections at the same relative proximodistal position in muscles from different embryos. Hindlimbs were separated from the spinal cord by severing the spinal nerves just distal to the dorsal root ganglia. Limbs were rinsed in low calcium $(0.1 \mathrm{~mm})$ Tyrodes for $30 \mathrm{~min}$, fixed in a triple aldehyde mixture of $1.5 \%$ paraformaldehyde (freshly prepared), $1.5 \%$ acrolein, and $1.5 \%$ glutaraldehyde in $0.1 \mathrm{M}$ cacodylate buffer, $\mathrm{pH}$ 7.2 , rinsed overnight in the same buffer, postfixed in $2 \%$ osmium/ $/ 0.1$ $M$ cacodylate buffer for $1.5 \mathrm{hr}$ at room temperature, rinsed in distilled water, dehydrated in ethanol and propylene oxide, and infiltrated with Epon/Araldite. The blocks were polymerized at $60^{\circ} \mathrm{C}$ and sectioned transverse to the long axis of the muscles, using an LKB ultramicrotome. Thin sections $(800-1000 \AA)$ were observed and photographed on a Phillips 301 transmission electron microscope.

\section{Results}

We have previously described the temporal course of innervation of the IFIB and PITIB muscles and found that innervation occurs in a series of discrete steps (Dahm and Landmesser, 1988). Since we will show in this paper that the pattern of innervation determines the spatial distribution of synapses, we have included a diagram summarizing the nerve ingrowth patterns of the IFIB and PITIB muscles (Fig. 1) in order to facilitate comparisons between the events of muscle innervation and AChR cluster formation.

The IFIB and PITIB muscle nerves form by St 27-28 by divergence of axons from the sciatic nerve. The IFIB muscle nerve enters near the proximal end of the IFIB, while the PITIB muscle nerve enters at a point midway along the proximodistal axis of the PITIB. Axons do not immediately invade the muscles, but wait as a large, loosely fasciculated mass on the surface of the muscles (Fig. 1 $\mathrm{A}$ ) within $200-300 \mu \mathrm{m}$ of the original muscle nerve entry point until St 29.5-30 (approximately 24 hr; Dahm and Landmesser, 1988). From St 30-31, intramuscular nerve trunks begin to grow into the muscles, parallel to the myotubes in the slow region of the IFIB and transverse to the myotubes in both the fast region of the IFIB and in the allfast PITIB (Fig. $1 B$; see Vogel and Landmesser, 1987 for myosin ATPase histochemistry). Subsequent ramification of nerves within the fast region of the IFIB and the fast PITIB occurs primarily by a process of reductive nerve branching [i.e., at each branch point a subset of the axons diverges to form a new branch, so that the branches become progressively smaller in diameter (Fig. 1C)]. In contrast, nerve ramification in the slow region of the IFIB occurs primarily by collateral sprouting from the shaft of axons whose parent growth concs arc in the distal 

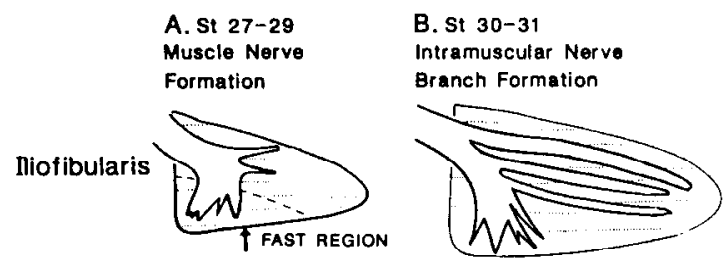

C. St $32-34$

Side Branch Formation
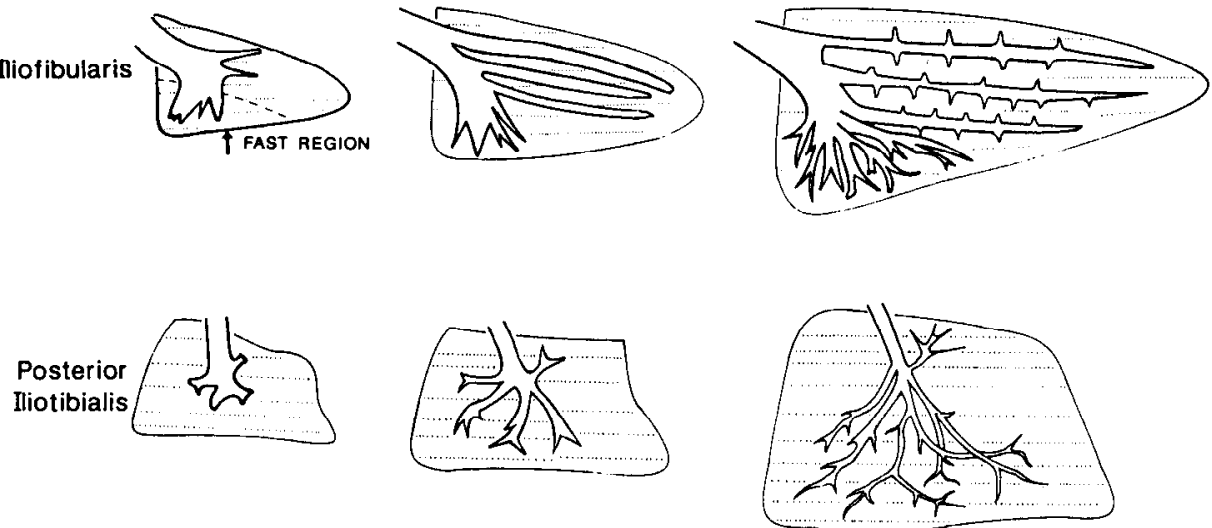

Figure 1. Schematic diagram showing the sequence of steps in the innervation of the IFIB and PITIB muscles. $A$, Axons diverged from the main sciatic nerve trunk to form the IFIB and PITIB muscle nerves by St 27-28. The axons remained near the ventral surface of the muscles, at the proximal end of the IFIB and at a point midway along the proximodistal axis in the PITIB until St 30 ( $24 \mathrm{hr}$ later). B. Axons began to grow into the muscles to form intramuscular nerve trunks at St 30 . In the slow region of the IFIB, the nerve trunks grew primarily parallel to the myotubes from proximal to distal without branching, while in the fast region of the IFIB (the boundary between the fast and slow regions is indicated by a dotted line in $A$ ) and in the all-fast PITIB the nerve trunks grew in predominantly transversely. $C$, Extensive ramification to form side branches occurred between St 32 and 34 in both muscles. The intramuscular nerve branching pattern differed between fast and slow muscle.

ends of the main longitudinal trunks. By St 32, this process forms a series of regularly spaced side branches oriented transverse to the main longitudinal nerve trunks (Fig. 1C). It is this difference in the nerve branching pattern that gives rise to the distinctly different patterns of synapse formation in adult avian fast and slow muscles: fast muscle receiving a single (few) synapse(s) and slow muscle receiving a spatially distributed series of endings (Ginsborg and Mackay, 1961). The temporal course of AChR cluster formation and synaptogenesis will therefore be described below with reference to these distinct events in the innervation of the IFIB and the PITIB muscles.

\section{The distribution of SV2 and R-BTX labeling at the adult neuromuscular junction}

The mature neuromuscular junction is characterized by the tight spatial colocalization of synaptic vesicles and AChRs at sites of nerve-muscle contact. This synapse can, therefore, be visualized effectively using SV2, an antibody that recognizes synaptic vesicles, and R-BTX, which binds to the AChR, to label the preand postsynaptic elements, respectively. In the adult chicken, SV2 (Fig. 2A) and R-BTX (Fig. 2B) labeling were colocalized and primarily restricted to the terminal region of axons and to the directly apposed myofiber membrane. In striking contrast to this adult distribution, during development, SV2 labeled axons along their entire length (see, for example, Fig. $4 A, C, E$ ). SV2 was also observed to label the growth cones of ciliary motoneurons in culture (Fig. $2 C, D$ ) indicating that it was expressed by motoneuron axons while they were still growing. Since SV2 and R-BTX delineate the mature synapse and were expressed during early development, the developmental course of synaptogenesis, described below, was examined using these markers. While it is possible that, in a developing muscle, a synapse could also occur where nerve terminals overlie a low density of receptors that are not recognizable as a cluster, as described in Materials and Methods, a synapse was defined as the colocalization of SV2 and R-BTX labeling.
The maturation of pre- and postsynaptic specializations during the period of initial innervation and motoneuron cell death

The appearance of AChR clusters is the first anatomically definable evidence of postsynaptic specialization at the neuromuscular synapse. Although the initial appearance of AChR clusters in the developing chick hindlimb has been described (Godfrey et al., 1988; Fallon and Gelfman, 1989), the precise relationship of the earliest AChR clusters to the ingrowing nerves was not directly assessed nor were their numbers quantified. In addition, although a small number of AChR clusters have been observed to form on aneural myotubes in vivo (Phillips et al., 1985; Fallon and Gelfman, 1989), it is not known to what extent nerve contact is required for AChR clustering to occur during normal development (but see Jacob and Lentz, 1979; Smith and Slater, 1983).

We first observed AChR clusters in the proximal region of the developing muscle masses in frozen sections of St 25-26 hindlimbs. Although muscle nerves have not yet formed, both the crural and sciatic trunks have penetrated into the limb at this stage and are in close proximity to the developing muscle masses (Tosney and Landmesser, 1985). AChR clusters first formed within muscles that were adjacent to major nerve trunks (Fig. $3 A, B$ ), but, surprisingly, most of the clusters formed on myotubes that were not in direct contact with nerve processes. This was also seen at St 27 when muscle nerves diverged to come into contact with the IFIB and PITIB muscles. Even though the IFIB muscle nerve had barely penetrated the muscle at this stage, numerous AChR clusters were induced on myotubes near the muscle nerve trunk and adjacent to the sciatic nerve trunk. Although most of these clusters were not in contact with a nerve process, they were within $100-200 \mu \mathrm{m}$ of the nerve trunk. AChR clusters were even induced within the IFIB muscle by the PITIB muscle nerve as it passed nearby the anterior region of the IFIB muscle on its way to the PITIB muscle (Fig. 3C,D), supporting our conclusion that clusters were being induced on myotubes that were not in direct anatomical contact with nerve. 

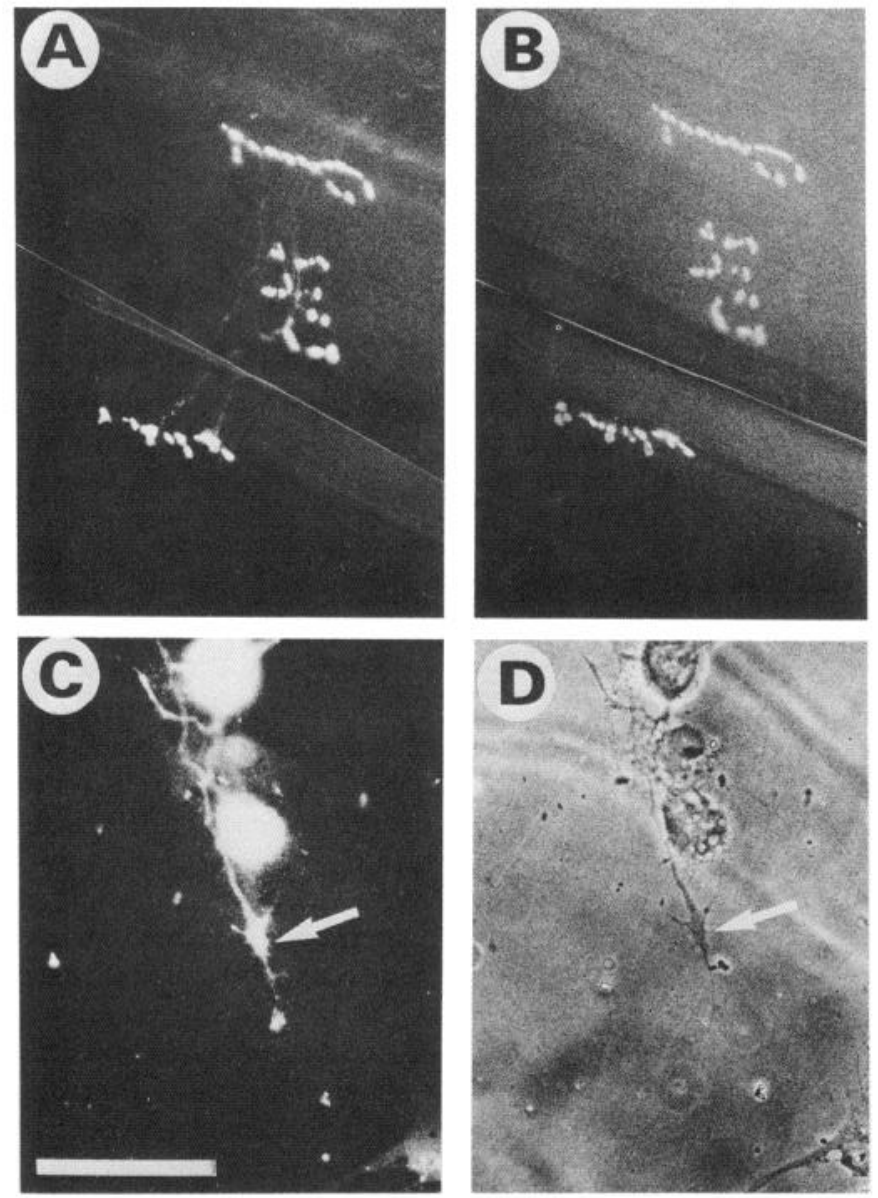

Figure 2. SV2 and R-BTX labeling in neuromuscular junctions of the adult chicken and SV2 labeling of cultured motoneurons. Whole-mount preparation of the IFIB of a 2-month-old chicken. $A$, In the adult, SV2 was highly concentrated at the presynaptic terminal region of axons. $B$, R-BTX labeling of postsynaptic AChRs in the same preparation revealed the tight spatial colocalization of synaptic vesicles and $\mathrm{AChR}$ clusters characteristic of the mature junction. Fluorescence $(C)$ and phasecontrast $(D)$ micrographs of ciliary neurons cultured on polyornithinecoated aclar for $24 \mathrm{hr}$. SV2 $(C)$ labeled the entire neuron, including the cell body and growth cone (arrows). Scale bar $=70 \mu \mathrm{m}, A, B ; 50 \mu \mathrm{m}$, $C, D$.

At St 30-31, when intramuscular nerve trunks began growing into the developing muscles (Fig. $1 B$; Dahm and Landmesser, 1988) AChR clusters were again observed to form on myotubes in the vicinity of the nerve trunks, but in many cases not in direct anatomical contact with SV2-labeled nerve profiles (Fig. $4 A, B)$. Since nerves grow from proximal to distal in the IFIB muscle with a known time course (see Fig. 1), it was possible to estimate that AChR clusters only appeared on myotubes several hours after the nerves had grown through. Thus, at early stages, AChR clusters were present in the proximal third to onehalf of the IFIB and absent from the distal third (even though the nerve trunks had entered the distal third of the muscle). This distribution again supported the suggestion that AChR clusters were being induced by the nerve. However, as at earlier stages, receptor clusters formed on myotubes that were not in direct anatomical contact with SV2-labeled nerves.

By St 32, shortly after side branches began to form in the IFIB (Fig. 1B; Dahm and Landmesser, 1988), receptor clusters began to disappear from around the main intramuscular nerve trunks and became restricted to the side branches (Fig. $4 C, D$ ), this process being essentially complete by St 34 (Figs. $4 E, F$ and $5 C, D)$. In the PITIB, a similar process occurred but with a longer time course. In this fast muscle (as in the fast region of the IFIB), receptor clusters disappeared more gradually from around the main intramuscular nerve trunks, and became restricted to secondary branches by St 35-36 (Fig. 5A,B).

Interestingly, we also observed a corresponding, gradual shift in the distribution of synaptic vesicle antigen in both muscles. SV2, which is highly localized to synaptic contacts at the mature neuromuscular junction (Fig. $2 A, B$ ), intensely stained the entire intramuscular nerve trunk and branches up to St 33, followed by increased localization of staining to the side branches (see, for example, Fig. 4). Figure 5 demonstrates that by St 35, the intensity of staining had diminished greatly within the main intramuscular nerve trunks in both the PITIB (Fig. $5 \mathrm{~A}$ ) and the IFIB (Fig. $5 C$ ). The staining was brighter in the side branches and was especially intense at sites of apparent synaptic contact where intense SV2 staining overlay AChR clusters.

In summary then, between St 30, when intramuscular nerve branches first form, and St 35-36, which is the end of the motoneuron cell death period, we observed a gradual restriction of both AChR clusters and SV2 antigen to sites of apparent synaptic contact. However, at early stages, AChR clusters did not appear limited to such contact sites, since they were induced on myotubes all along the length of nerve trunks as well as on myotubes at some distance away from them.

Because nerve-induced AChR cluster formation in tissue culture has been observed to occur only at points of nerve-muscle contact (Fischbach and Cohen, 1973; Anderson and Cohen, 1977; Frank and Fischbach, 1977), it was important to show that the AChR clusters that were induced some distance from the nerve in vivo were in fact not contacted by nerve processes, because the possibility exists that some early processes might be SV2 negative. This was the easiest to verify in the IFIB because, at St 30 , the main nerve trunks are composed of large bundles of naked, small diameter axons (see, for example, Fig. $7 \mathrm{~A}$ ) that grow the entire length of the muscle without forming side branches. AChR clusters are induced on myotubes within several hundred microns of these nerve trunks (see Fig. 4A,B). We confirmed that axons do not extend to these clusters by labeling the nerves with the lipid soluble fluorescent dye, DiI (Fig. 6A,C). This dye labels axons to their growth cones and allows single axons to be visualized in tissue culture (see Honig and Hume, 1986). Thus, we confirmed by this technique as well as by labeling axons with the neuron-specific C-2 antibody (Fig. $6 B, D)$ that side branches did not extend from the nerve trunks at this stage and that the vast majority of these clusters were, therefore, not in direct contact with nerve processes. Finally, the unbranched nature of the axons within the St 30 nerve trunks was confirmed in a series of muscles by anterograde labeling of small numbers of axons with HRP (Fig. 6E). This technique, which has been shown to label motor axons to their growth cones (Tosney and Landmesser, 1985), allowed us to visualize long lengths of single axons within these nerve trunks and to confirm the absence of side branches.

To ascertain that these early clusters were in fact being induced by the nerve, we examined the IFIB and PITIB muscles in $4 \mathrm{St} 28$ hindlimbs from embryos whose neural tube had been removed at St 16-17. Analysis of serial frozen sections doublelabeled using SV2 and R-BTX revealed that in these muscles devoid of nerve, there were only $1.5 \pm 0.6 \mathrm{AChR}$ clusters per 

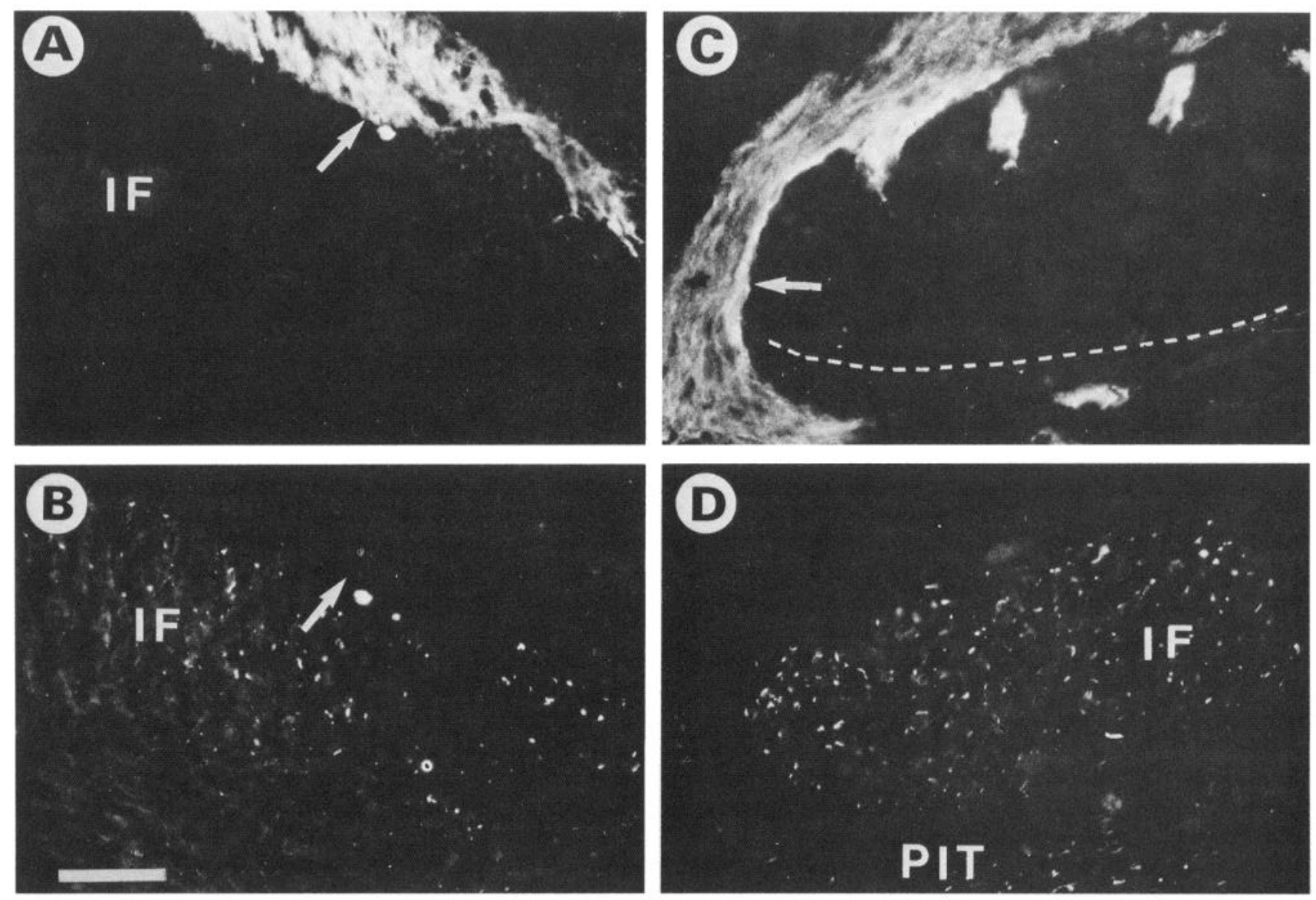

Figure 3. AChR cluster formation does not require nerve contact. Frozen cross sections through the IFIB and PITIB muscles double-labeled using SV2 $(A, C)$ and R-BTX $(B, D)$. Although muscle nerves have not yet formed in this St 26.5 embryo $(A)$, the sciatic nerve trunk $($ arrow) is in close proximity to the developing IFIB $(I F)$ and AChR clusters $(B)$ have formed on myotubes that are within $100-200 \mu \mathrm{m}$ of the nerve trunk. Note that none of the receptor clusters are in direct anatomical contact with a nerve profile at this stage. By St $29(C, D)$, when the PITIB muscle nerve (arrow) has reached the PITIB (PIT), AChR clusters $(D)$ were observed on myotubes in the IFIB that were near the passing PITIB nerve. The dotted line in $C$ denotes the boundary between the two muscles. Scale bar $=50 \mu \mathrm{m}$.

muscle compared to $617 \pm 117$ per muscle for the control PITIB, and only $5.5 \pm 2.3$ per muscle compared to $1146 \pm 181$ per muscle for the control IFIB $(n=4$, mean \pm SEM). This represents less than $0.5 \%$ of the number of AChR clusters normally present in these muscles at St 28 . Thus, these results strongly support the idea that the nerve induces the vast majority of AChR clusters that form by St 28 , including those not in direct anatomical contact with the nerve.

\section{Ultrastructural observations of early stages of innervation}

At St 30, just at the onset of the motoneuron cell death period, careful examination of cross sections of the IFIB indicated that virtually all of the axons within the muscle were within several large nerve trunks containing hundreds of small-diameter $(<1$ $\mu \mathrm{m})$ naked axons. Such trunks were easily correlated with those that we visualized with immunostaining at the light microscope level (see Fig. 6). Approximately half of such a trunk is shown in Figure $7 \mathrm{~A}$. Especially striking was that at this developmental stage, virtually none of the axons (with the possible exception of those at the growing distal end of the nerve) were in contact with myotubes, but were separated from them by processes of cells that loosely ensheathed the nerve trunks (indicated by stars in Figure $7 A$ ). From previous observations (Dahm and Landmesser, 1988) these are likely to be neural-crest-derived pre- sumptive Schwann and/or other support cells. Thus, prior to side branch formation, most axons were embedded within tightly packed nerve trunks, surrounded by other axons.

At early stages (St 30), some of the profiles within the nerve trunks were somewhat enlarged and electron luscent, with abundant vesicular profiles and smooth endoplasmic reticulum. These appeared to be growth cones. However, even up to St 32-33 many axons within the nerve trunks contained irregularly shaped membranous vesicular profiles, as well as occasional, larger dense core vesicles. Several such profiles are indicated by arrows in Fig. $7, B$. This fairly abundant membranous material along axons may be an ultrastructural correlate of the early distribution of the SV2 antigen throughout the entire length of axons.

At St 32-33, side branches containing smaller numbers of axonal profiles were observed coming into closer contact with adjacent myotubes. The axonal profiles within these side branches contained numerous accumulations of small, clear vesicles ( $\mathrm{ar}$ row, Fig. 7C), with some larger dense core vesicles present as well. However, as at St 30, we only rarely observed direct anatomical contact between axonal profiles and myotubes. As shown in Figure 7, $C$, the axonal profiles within side branches were for the most part separated from adjacent myotubes by the processes of presumptive Schwann cells (stars in Fig. 7C). In addition, processes of an unidentified cell type (asterisks in 

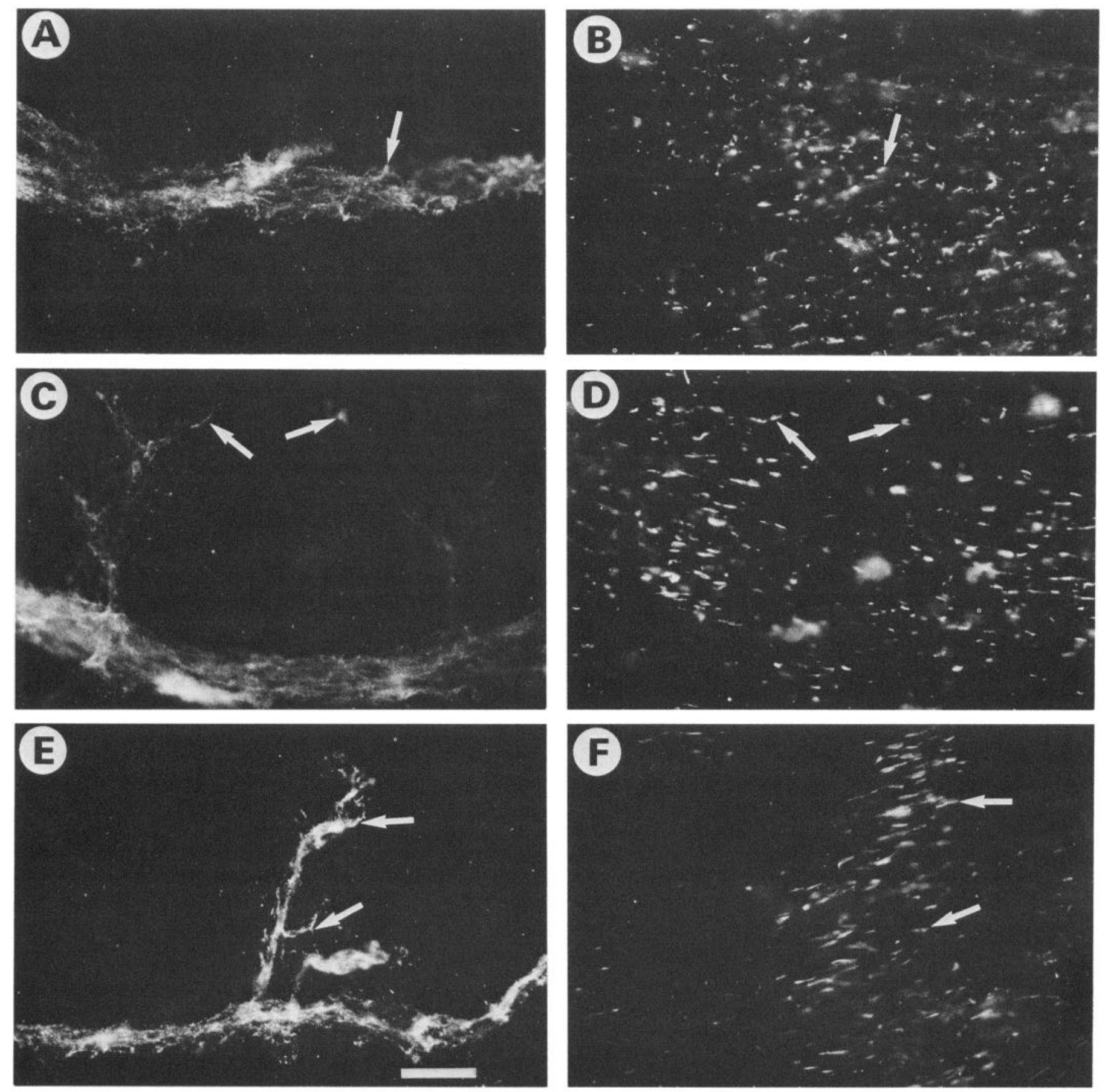

Figure 4. AChR clusters become localized to side branches in the slow region of the iliofibularis muscle. Whole-mount preparation of IFIB muscles, myotubes run from left to right. Axons (left panel) are labeled with SV2 and AChR clusters (right panel) are labeled with R-BTX. By St $30 \mathrm{AChR}$ clusters $(B)$ had formed on myotubes in the vicinity of the main intramuscular nerve trunks $(A)$, several hours after the nerve trunks had grown through, suggesting that they were induced by the nerve. However, AChR clusters formed on myotubes that were not in direct contact with the nerve. Arrow indicates cluster that was colocalized at this stage and helps to indicate the position of the nerve trunk with respect to the clusters. Many of the clusters are $100 \mu \mathrm{m}$ away from the nerve trunk. By St 32, as side branches $(C)$ formed, receptor clusters $(D)$ began to disappear from around the main nerve trunks and to become restricted to the side branches. Two side branches are visible in $(C)$ and the spatial distribution of receptor clusters in $(D)$ reflects their positions, i.e., there are no clusters in the center of the photograph between the branches. This process of restriction of receptor clusters $(F)$ to side branches $(E)$ is essentially complete by St 34 . However, although receptor clusters are restricted to side branches by this stage, many are still not colocalized to an SV2-labeled nerve process. Arrows $(C-F)$ indicate nerve profiles and corresponding colocalized receptor clusters on side branches. Scale bar $=50 \mu \mathrm{m}$.

Fig. 7C) were often interposed between the side branches and the surfaces of the myotubes proper. All of the nonaxonal processes contained ribosomes and endoplasmic reticulum and could be clearly distinguished from axons on that basis. However, by
St 32-33, we did observe portions of some nerve branches in direct contact with some myotubes (arrows, Fig. 7D); though once again most of the nerve was separated from the myotube surface by another cell type (stars, Fig. 7D). Early presumptive 

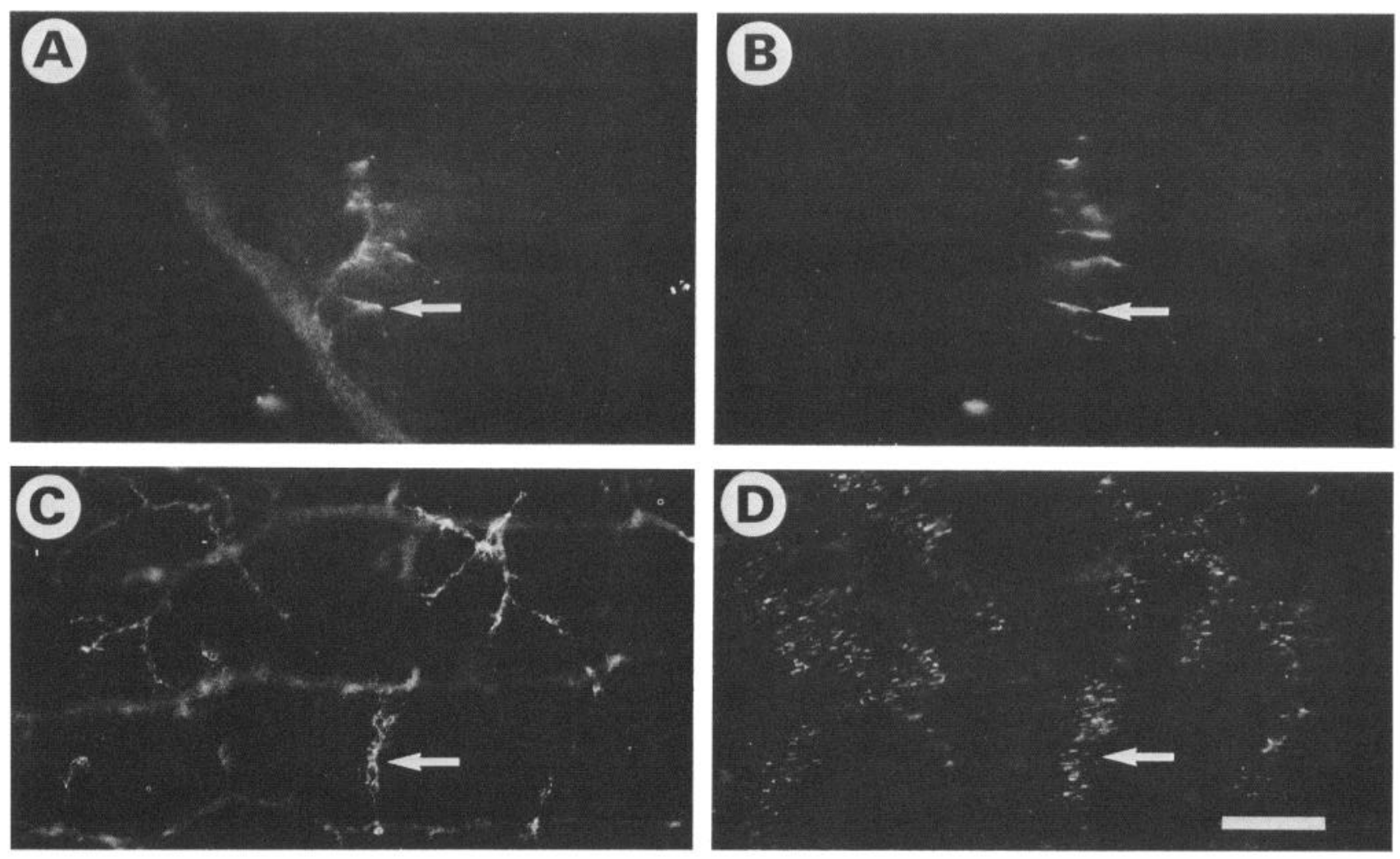

Figure 5. SV2 labeling becomes localized to secondary branches in both the posterior iliotibialis and iliofibularis muscles during normal development. Whole-mount of a St 35 PITIB $(A, B)$ and IFIB $(C, D)$ muscle double-labeled with SV2 to visualize the axons $(A, C)$ and R-BTX to visualize the AChR clusters $(B, D)$. $A$ and $B$, At this stage SV2 staining is much brighter in the side branch than in the trunk from which it emerged and AChR clusters are completely restricted to the side branches. (Arrows point to colocalized cluster and nerve profile.) $C$ and $D$, In this low magnification view of an IFIB muscle whole-mount, the myotubes and main intramuscular nerve trunks run left-to-right and the side branches (1 is indicated by an arrow in C) emerge transverse to the intramuscular nerve trunks. Both SV2 labeling and R-BTX labeled AChR clusters become restricted to side branches (arrow) by St 35 (AChR clusters become restricted to side branches sooner than does SV2 staining, see Fig. 4). Scale bar $=50 \mu \mathrm{m}(A, B), 150 \mu \mathrm{m}(C, D)$.

synapses (inset, Fig. 7D) were also observed where nerve terminals containing sparse vesicles (star) came into direct apposition with the myotube surface. Few obvious synaptic specializations, such as large accumulations of vesicles presynaptically or pre- and postsynaptic densities were observed. However, this may not be surprising since most of these synapses would have had to have been less than 24-hr old (side branches do not even begin to form until late St 30 which is only $24 \mathrm{hr}$ earlier than St 32 when these contacts were observed). This is consistent with tissue culture observations where identifiable functional synaptic contacts made between Xenopus motoneurons and myotubes for less than $24 \mathrm{hr}$ often contained few ultrastructural specializations (Takahashi et al., 1987).

We did not make observations at later stages since it was not our intention to study the development of synapses at the electron microscope level. However, our observations confirm light microscopical observations that indicate that, at the onset of the motoneuron cell death period, most axons are not in direct contact with myotubes, and that it is only after side branch formation that apparent synaptic contacts can be observed. Their sparsity and lack of structural specialization clearly preclude quantification of synapses with the EM at these critical early stages of nerve-muscle interaction. For this reason we chose to quantify synaptic contacts using immune staining of specific synaptic components as described in the next section.
Synapse formation during normal development and following activity blockade

Although at the earliest stages, most AChR clusters were not colocalized with nerve processes, even by $\mathrm{St} 27$ a small number of colocalized receptor clusters could be demonstrated in frozen cross sections stained with SV2 and R-BTX (Fig. 8A,B). The proportion of such colocalized clusters gradually increased until St 36 when most were closely associated with nerve processes (Fig. $8 C, D$ ). Since we defined such colocalized clusters as synapses, we first assessed the temporal course of synapse formation during development by quantifying the degree of colocalization of AChR clusters and nerve profiles both during normal development and following activity blockade. These results are presented graphically in Figure 9. Although AChR clusters were observed on myotubes as early as St 25 , none were found to be in direct anatomical contact with nerve profiles until St 27-28, coincident with the divergence of axons from the sciatic trunk to form the IFIB and PITIB muscle nerves. This initial appearance of anatomically defined synapses also correlated temporally with the ability of these muscles to contract in response to nerve stimulation (Landmesser and Morris, 1975). However, only $3 \%$ of the total AChR clusters in the IFIB and $10 \%$ of those in the PITIB were actually colocalized to SV2-labeled nerve profiles at this stage. This number slowly increased throughout 

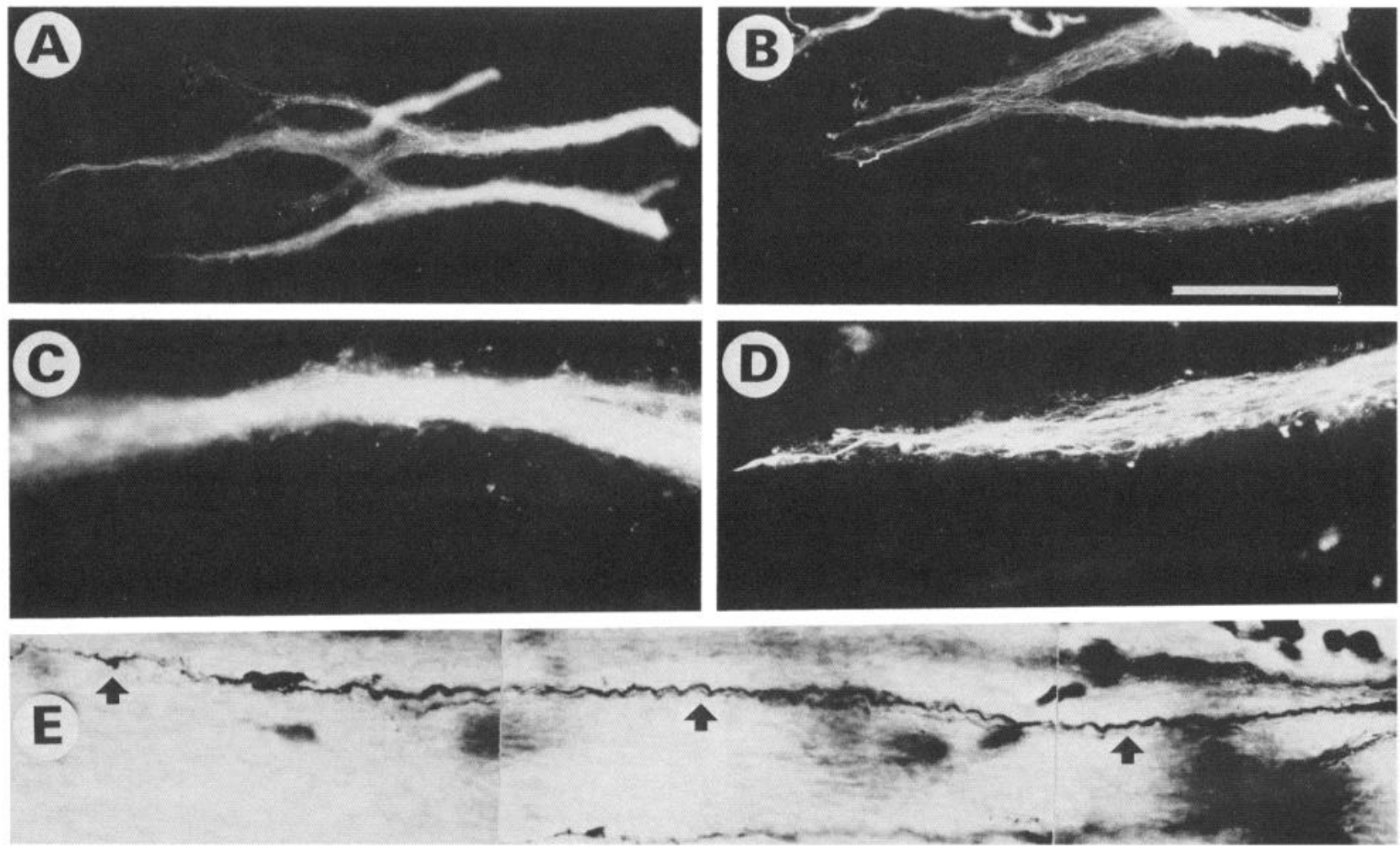

Figure 6. Axons within the main intramuscular nerve trunks in the iliofibularis muscle are unbranched at St 30 . Low $(A, B)$ and high $(C, D)$ magnification views of 2 different IFIB muscles labeled with the lipid-soluble dye, DiI $(A, C)$ or the axon-specific antibody, C-2 $(B, D)$. $A$ and $B$, All of the intramuscular nerve trunks in the anterior (slow) region of the IFIB are visible. $C$ and $D$, Inspection at higher magnification confirmed that the axons within these trunks are unbranched at this stage. $E$, In addition, inspection of single axons anterogradely labeled by small injections of HRP showed that they grew the entire length of the muscle within the large intramuscular nerve trunks without branching. Arrows indicate the small fascicle within the intramuscular nerve trunk that was labeled with HRP. Myotubes run from right (proximal) to left (distal) in this figure. Scale bar $=140 \mu \mathrm{m}(A, B), 80 \mu \mathrm{m}(C, D)$, and $60 \mu \mathrm{m}(E)$.

the cell death period, so that by St 36, most AChR clusters (70$90 \%$ ) were associated with presynaptic profiles. The process of colocalization occurred with a roughly similar time course in both muscles (Fig. 9A,B).

Activity blockade accelerated the process of colocalization in both muscles (Fig. 9). For instance, in the slow region of the IFIB, essentially all of the AChR clusters (94\%) were colocalized to SV2-labeled nerve profiles by St 32 (compared to only $61 \%$ at this stage during normal development). The figures for percentage colocalization reflect 2 processes: synapse formation and the regression of non-nerve-associated AChR clusters, and either one or both could be accelerated by activity blockade. Therefore, measuring percentage colocalization did not allow us to distinguish between these 2 mechanisms, nor did it give a measure of the number of synapses actually formed during the cell death period. Since our intention was to determine the relationship (if any) between motoneuron survival and synapse formation, we needed to quantify the total number of synapses during normal development and following activity blockade. To avoid the complicating feature that the IFIB is partially slow and slow myotubes have multiple synapses, we chose to quantify synapses in the all fast PITIB muscle.

We counted the total number of synapses formed in the entire PITIB muscle from St 24-36 both during normal development and following activity blockade (Table 1). We also counted the total number of synapses in the IFIB from St 24-29 in order to assess the generality of our observations (Table 2). During normal development the first colocalized AChR clusters were observed at $\mathrm{St} 27$ in both muscles, $32 \pm 12$ total synapses per muscle in the PITIB and $17 \pm 8$ per muscle in the IFIB $(n=4$

Figure 7. Most axons are not in direct contact with myotubes at the onset of the cell death period. $A$, Cross section through 1 of the large intramuscular nerve trunks located in the slow region of a St 30 IFIB muscle. At this stage (the beginning of the cell death period) the nerve trunk is composed of large numbers of unmyelinated, small-diameter axons which are separated from the myotubes $(m)$ by processes of presumptive Schwann cells (stars). Note that none of the axons are in contact with the myotubes. B. Higher magnification view of a similar nerve trunk at St 33. The axons contain large amounts of membranous material, including irregularly shaped vesicular profiles and occasional dense core vesicles (arrows). C, Section through a side branch as it emerges from an intramuscular nerve trunk in a St 33 IFIB muscle. Axons within side branches also contain numerous vesicular profiles (arrow), however, similar to St 30, most axons were not in direct contact with the myotubes ( $m$ ) and in many cases there was an intervening Schwann cell (star). D. The rare presumptive nerve contacts that were observed (arrow) showed little or no synaptic specialization (inset). Myotubes $(\mathrm{m})$ were identified on the basis of the presence of clusters of contractile filaments which were more obvious at higher magnification (inset). Scale bar $=1 \mu \mathrm{m}(B, C, D), 5 \mu \mathrm{m}(A)$. 

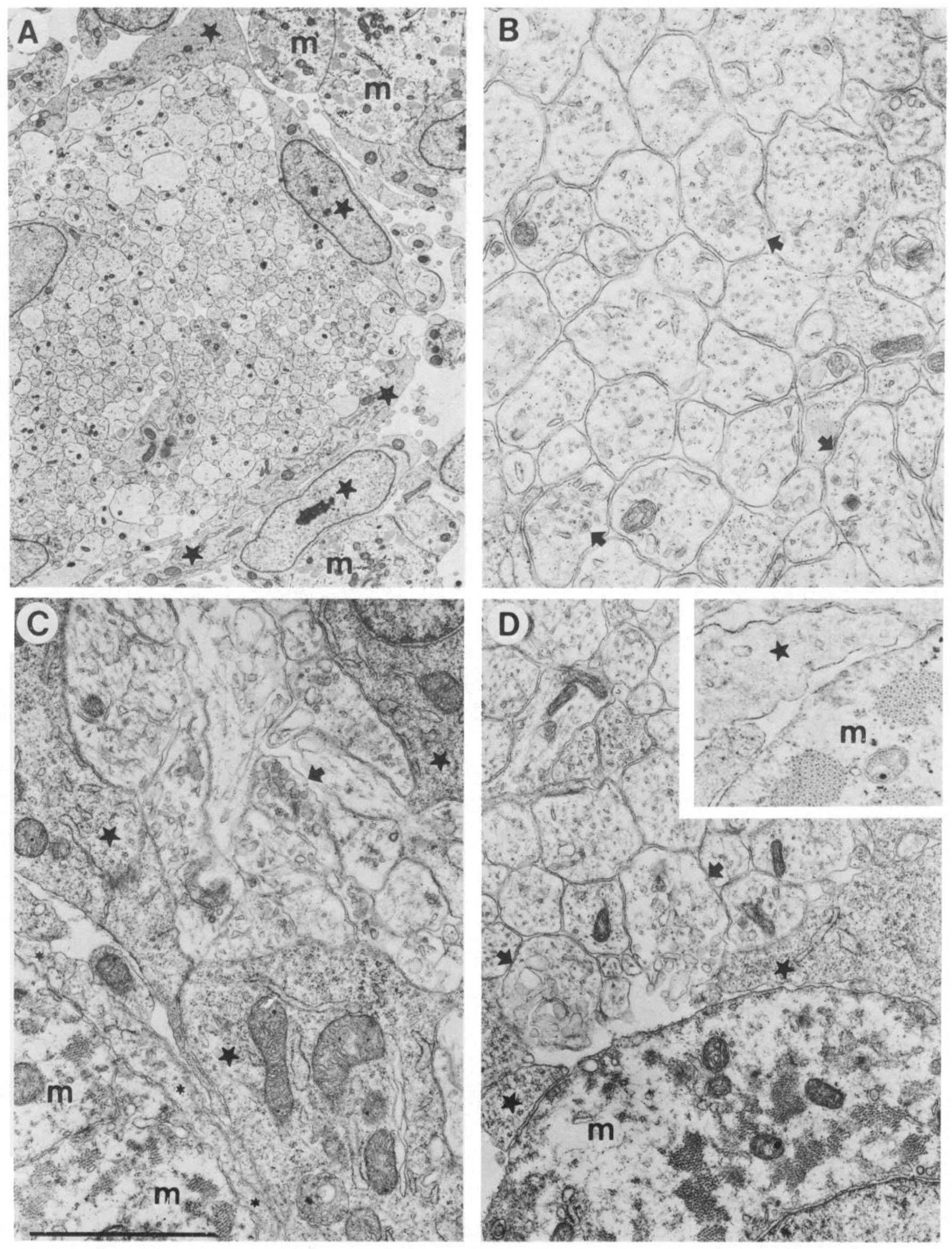

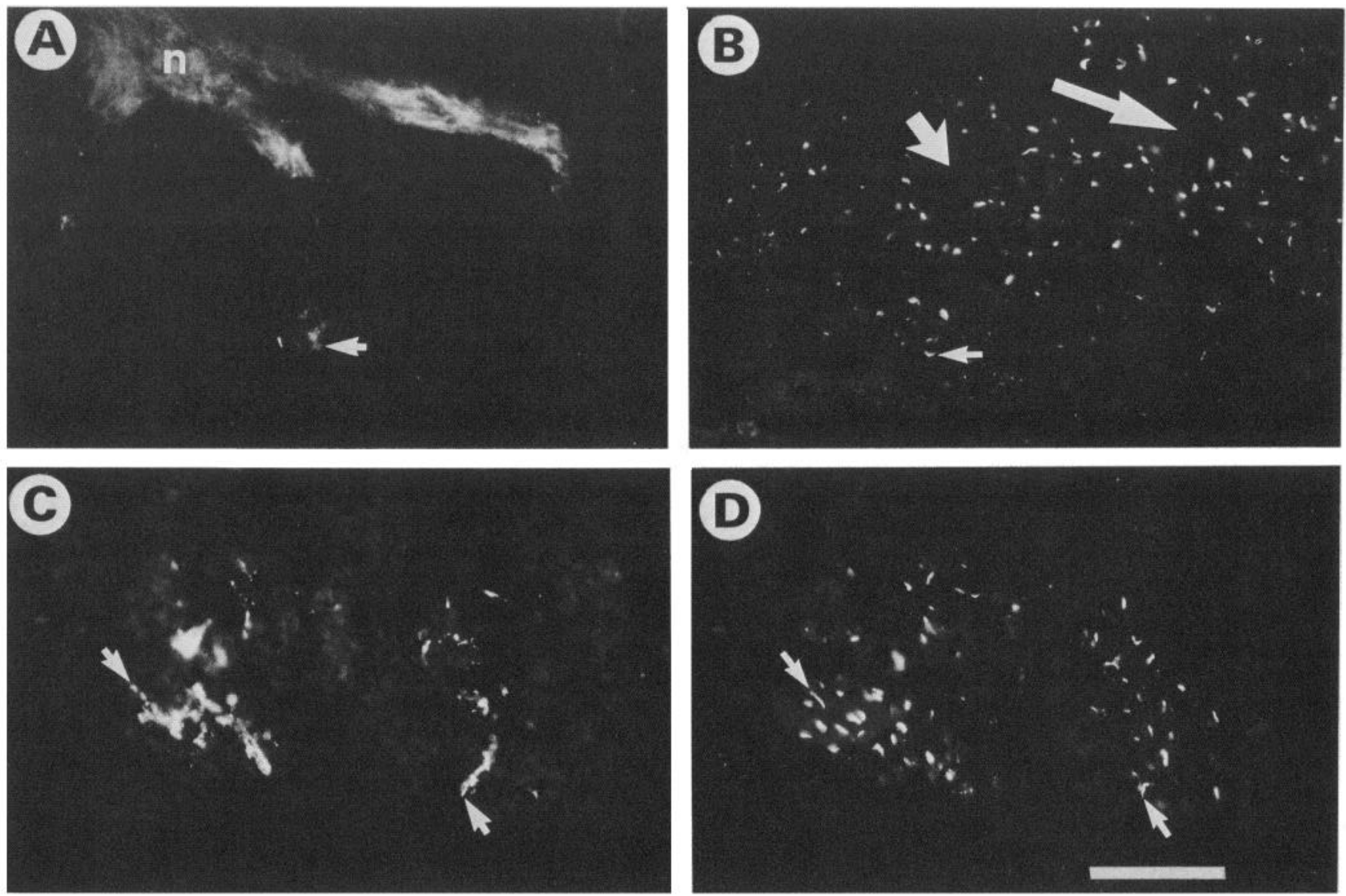

Figure 8. The distribution of SV2 and R-BTX labeled profiles in frozen cross sections of the posterior iliotibialis muscle during normal development. Analysis of frozen cross sections of the PITIB confirmed that many receptor clusters were not colocalized to nerve profiles during development. Axons are labeled with SV2 $(A, C)$ and AChR clusters are labeled with R-BTX $(B, D) . A$, By St 27 the muscle nerve $(n)$ had entered the PITIB. $B$, Most receptor clusters were located within $100 \mu \mathrm{m}$ of the nerve (large white arrows), but only a few were in contact with a nerve profile (small arrow). $C$ and $D$, However, by the end of the cell death period (St 36$)$ most of the clusters were nerve contacted. Arrows in $C$ and $D$ indicate several such nerve-associated clusters and corresponding nerve profiles. Scale bar $=50 \mu \mathrm{m}$.

for each muscle, mean \pm SD). This correlates well with physiological observations that this is the earliest stage at which these muscles will contract in response to nerve stimulation (Landmesser and Morris, 1975; Landmesser, 1978).

During normal development, the total number of synapses in the PITIB increased from 32 at St 27 to approximately 2000 at the onset of the motoneuron cell death period (St 30). Since the PITIB at this stage contains $200 \pm \mathbf{4 0}$ myotube clusters (Tanaka and Landmesser, 1986), there are more than enough synapses for each myotube cluster. Because these early clusters are composed of 4-5 primary myotubes as well as associated myoblasts

Table 1. The number of synapses in the PITIB during normal development and following activity blockade

\begin{tabular}{lccl}
\multicolumn{5}{l}{ Synaptic AChR clusters } \\
\cline { 2 - 4 } Stage & Control & dTC & Ratio \\
\hline 28 & $132 \pm 12$ & 125 & 1.0 \\
29 & 279 & $440 \pm 88$ & 1.6 \\
30 & 2223 & 6913 & 3.1 \\
33 & $7725 \pm 1367$ & $17,201 \pm 2384$ & 2.2 \\
36 & 20,783 & 28,337 & 1.4
\end{tabular}

Ratio $=\mathrm{dTC} /$ Control, $n=2-5$, mean \pm SEM, except where $n=2$. which will form secondary myotubes (L. T. Landmesser, unpublished observations), at the onset of cell death there are roughly 2 synapses per primary myotube. By St 33, the middle of the cell death period, the number of synapses has increased to nearly 8000 ; during this same time period the number of myotubes has increased to approximately 3000 , so, again, the number of synapses is roughly double the number of primary myotubes. From St 34-38 a large number of secondary myotubes form (McLennan, 1983; Fredette and Landmesser, 1990). It is therefore possible that the later increase in synapses, reaching approximately 21,000 by St 36 , reflects synapse formation onto these secondary myotubes.

Activity blockade resulted in a 3-fold increase in the number

Table 2. The number of synapses in the IFIB during early development

\begin{tabular}{lc} 
Stage & Number of synapses \\
\hline 27 & $17 \pm 8$ \\
28 & $64 \pm 9$ \\
29 & $216 \pm 39^{a}$
\end{tabular}

$a n=2$, avg \pm difference from the avg; all others, $n=4$, mean \pm SEM. 

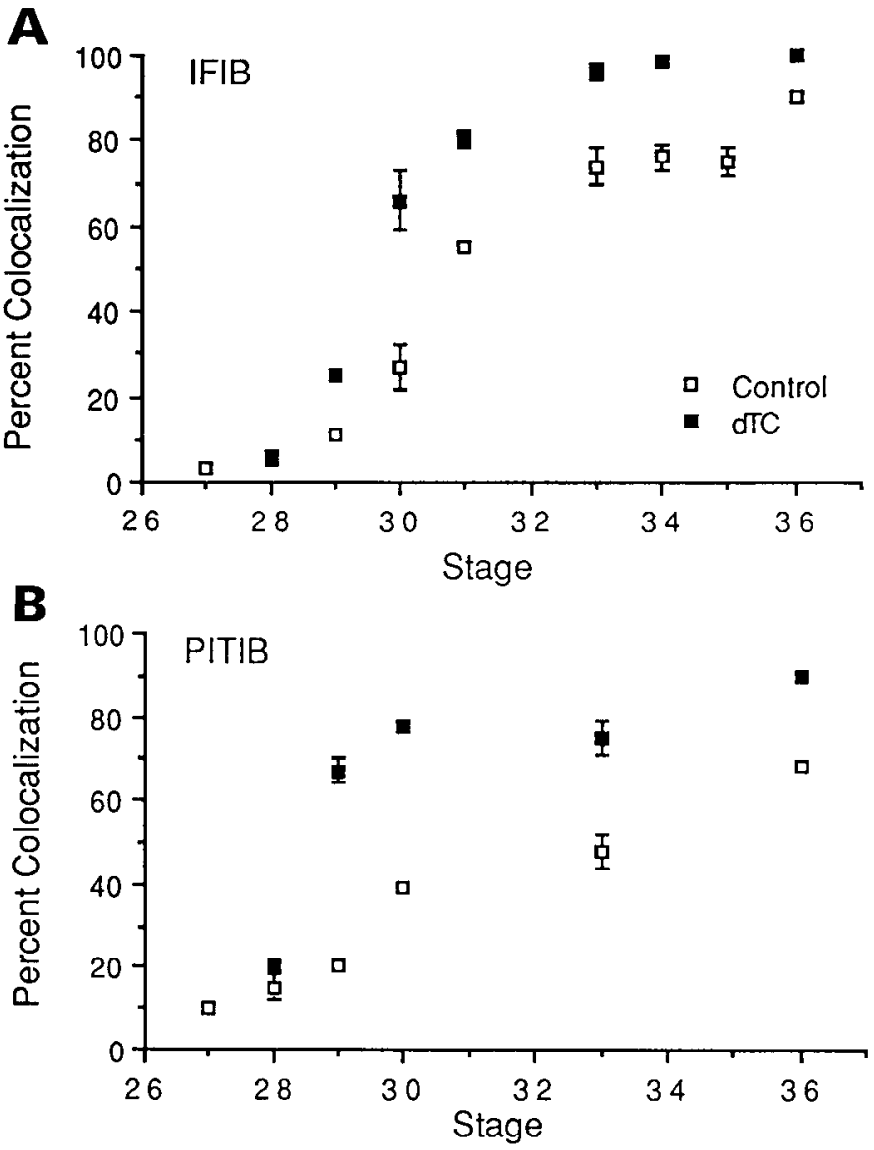

Figure 9. Quantification of the temporal course of synapse formation in whole-mounts of the iliofibularis and the posterior iliotibialis muscles during normal development and following activity blockade. The percent of AChR clusters that were contacted by an SV2 labeled nerve profile in the IFIB $(A)$ and the PITIB $(B)$ increased steadily during normal development in both muscles (open squares). Nerve-contacted clusters first appeared in the developing muscles at St 27 and $70-90 \%$ of the clusters were colocalized by the end of the cell death period (St 36). Activity blockade accelerated the process of colocalization (filled squares) so that $90-100 \%$ of the clusters in both muscles were colocalized to nerve profiles by the middle of the cell death period (St 33).

of synapses over control values by $\mathrm{St} 30$, the beginning of the cell death period, and a 2 -fold increase during the remainder of the cell death period (Table 1). Activity blockade increased the total number of synapses in the PITIB by increasing the rate of synapse formation (Fig. 10). During normal development, the rate of synapse formation increased steadily from 8 synapses/ $\mathrm{hr}$ at St 27-28 to 251 synapses/hr by St 36 . Following dTC treatment, there was a large transient increase in the rate of synapse formation at St 29-30 followed by a decrease to control levels by St 36. Since this large change in the rate of synapse formation preceded the onset of normal cell death in the lumbosacral motor column, these data strongly suggest that synapse formation may be an important determinant of motoneuron survival.

We previously found (Dahm and Landmesser, 1988) that activity blockade also increased and accelerated the process of nerve branching in the slow region of the IFIB so that a plateau was reached by St 32 following curarization. In fact, there was a strong correlation between the degree of synapse formation (i.e., the percent colocalization of nerve profiles and AChR clusters) and the number of side branches $/ \mathrm{mm}$ nerve trunk in the

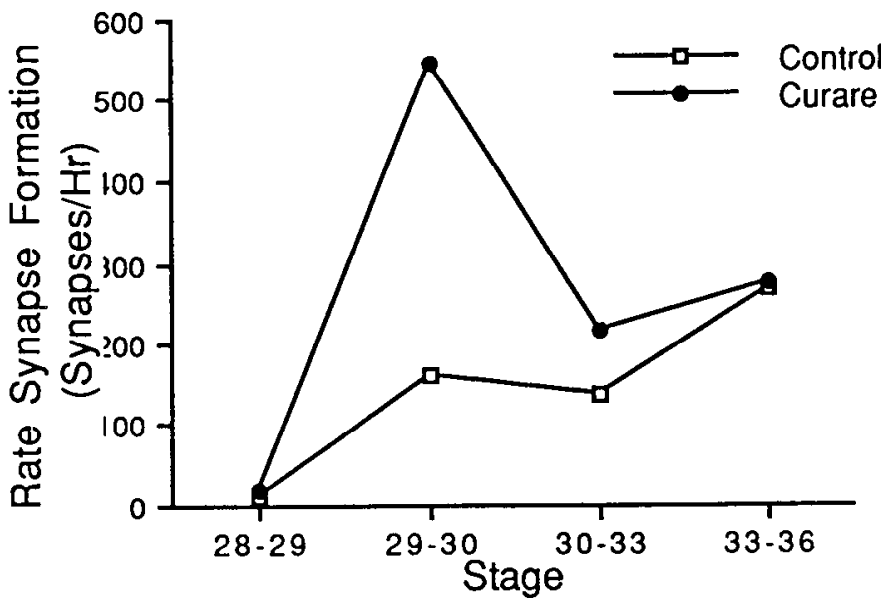

Figure 10. The rate of synapse formation in the posterior iliotibialis muscle is increased following activity blockade. The rate of synapse formation during normal development and following activity blockade was estimated by subtracting the number of nerve contacted AChR clusters present at the younger stage from the number at the older stage and dividing by the time in hours between the 2 stages. The rate of synapse formation was initially low during the nerve "waiting period" from St 28-29 and increased 14-fold as the intramuscular nerve trunks grew into the muscle (St 29-30). The rate of synapse formation remained steady at about 150 synapses/hr during the first half of the cell death period and began to increase in the second half. This latter increase may have been in response to the generation of secondary myotubes. Although the rate of synapse formation was similar in activity-blocked and normal muscles at St 28-29, it increased 27-fold as the intramuscular nerves grew in (St 29-30). This represented a doubling in the rate of synapse formation which led to a 3-fold increase in the number of synapses in dTC vs control muscles by St 30 . This large increase in the rate of synapse formation was transient (it occurred prior to the onset of normal motoneuron cell death), dropping to control levels near the end of the cell death period (St 33-36).

slow region of the IFIB both during normal development and following activity blockade (Fig. 11). This supports our anatomical observations, discussed in the following section, that side branches are the sites of synapse formation in this region. The increase in synapse number that occurred during normal development as well as that which occurred in response to activity blockade correlated with increased nerve branching in the PITIB. Taken together, these data suggest that the pattern of nerve branching is a major determinant of the distribution and the number of synapses in muscles.

We did not attempt to make counting corrections for either the number of synapses or the number of AChR clusters. We found that the average length of receptor clusters measured in muscle whole-mounts did not vary significantly from St 31-37 in either control or curare-treated embryos (Fig. 12). In fact, the distribution of cluster lengths was nearly identical between agematched control and activity blocked embryos at both St 31 and $\mathrm{St} 37$, and very similar between the 2 stages. However, we did observe differences in the length of the presynaptic profiles that were apposed to the clusters.

Because the SV2 antigen is not restricted to sites of nervemuscle contact during early stages of development (St 35 and younger), but is instead distributed all along the length of the axons, it was difficult to measure the actual lengths of presynaptic profiles apposed to AChR clusters in muscle whole-mounts. However, we could estimate their relative length by dividing synapses into 2 categories: those that were apposed by a pre- 


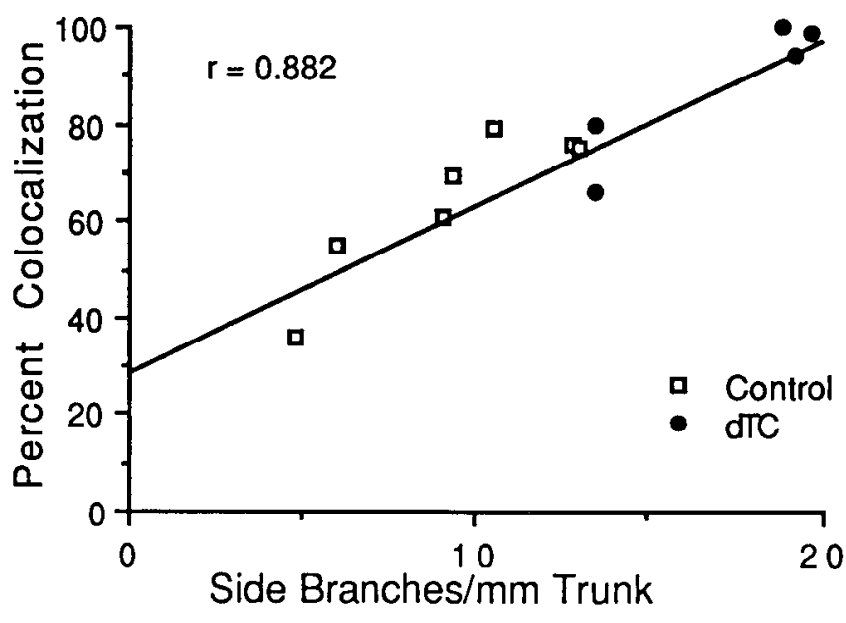

Figure 11. The correlation between synapse formation and side branch formation in the slow region of the iliofibularis during normal development. The percent of nerve-contacted AChR clusters increased in parallel with the number of side branches $/ \mathrm{mm}$ nerve trunk in the slow region of the IFIB during normal development (open squares) and following activity blockade (filled circles). Data taken from St 30-36 muscles.

synaptic profile over less than half their length and those that were apposed over greater than half their length. In so doing we observed that during normal development the majority of presynaptic profiles occupied less than half the length of the receptor cluster, even at the end of the cell death period (St 36; see Table 3 ). In fact, during the early stages of synapse formation (up to St 32), many clusters were contacted along only a very small portion of their total length by what appeared to be a single bouton (not shown).

In addition to accelerating the process of colocalization and increasing the total number of synapses in the muscles, activity blockade also enhanced the extent to which presynaptic nerve profiles occupied the entire length of receptor clusters, i.e., activity blockade increased synapse length. Following activity blockade, most of the receptor clusters were colocalized with SV2-labeling along more than half of their length by St 33 (Table 3). Because there were no significant differences in either the length of AChR clusters or in the extent to which their length was apposed by a presynaptic profile at $\mathrm{St} 30$ between control and activity-blocked embryos (Fig. 12, Table 3), we feel that the relative difference in the number of synapses in control and dTC treated muscles is accurate as reported for $\mathrm{St} 30$ and younger. However, since the percentage of synapses that are apposed

\begin{tabular}{|c|c|c|}
\hline \multirow[b]{2}{*}{ Stage } & \multicolumn{2}{|c|}{$\%$ synapses greater than half occupied } \\
\hline & Control $(n)$ & $\operatorname{dTC}(n)$ \\
\hline 30 & $24 \pm 4$ & $29 \pm 3$ (2) \\
\hline 31 & $17 \pm 3$ & $35 \pm 21(5)$ \\
\hline $32-33$ & $30 \pm 12(6)$ & $68 \pm 15(3)$ \\
\hline $34-35$ & $39 \pm 9 \quad(8)$ & $79 \pm 10(3)$ \\
\hline $36-37$ & $53 \pm 2$ & $94 \pm 3$ (2) \\
\hline
\end{tabular}

Mean \pm SEM, except for $n=2$ where avg \pm the difference from the avg is given.
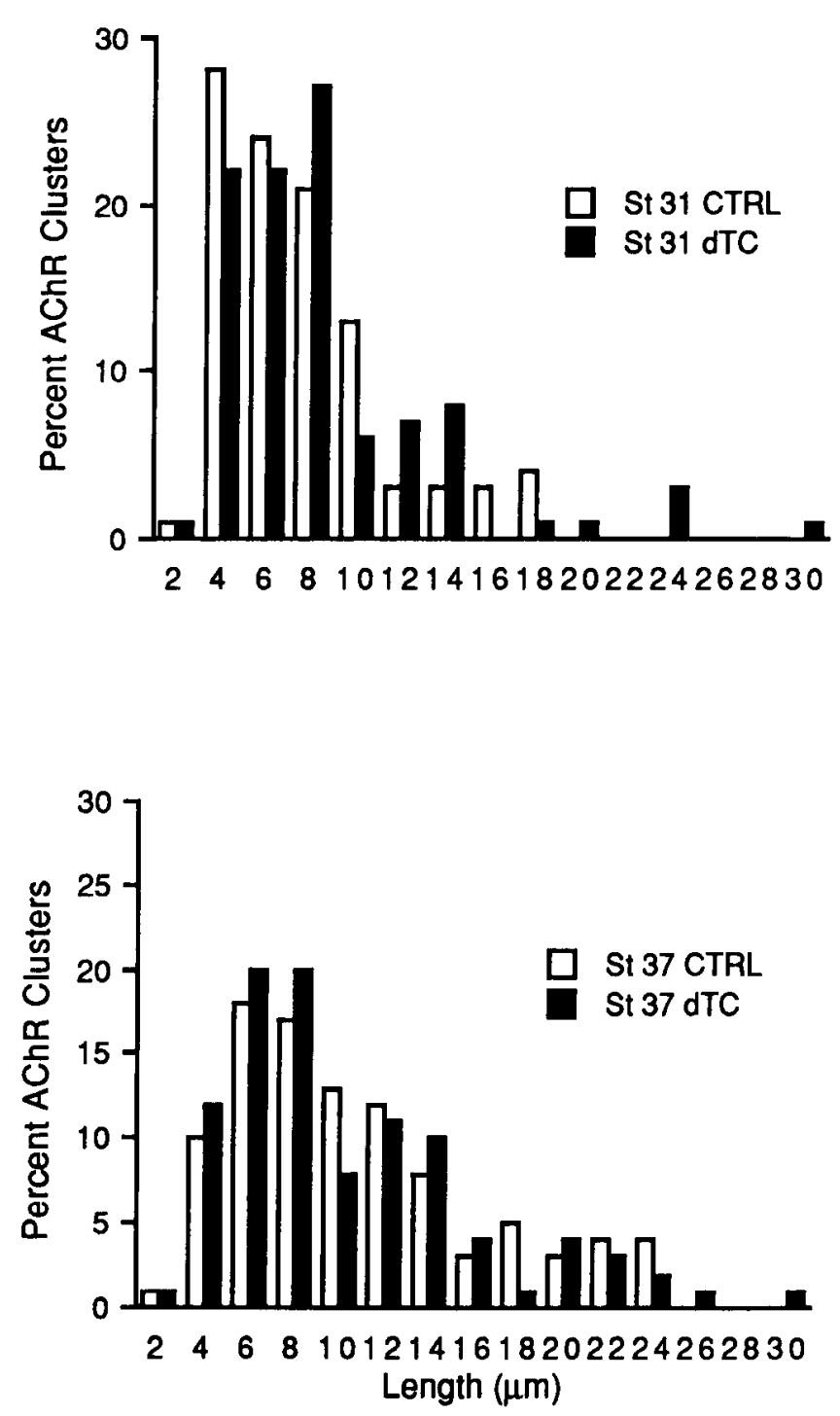

Figure 12. The length of AChR clusters remains constant throughout the cell death period and is not affected by activity blockade. AChR cluster lengths were measured from negatives of whole-mounts of the IFIB muscle at St $31(A)$ and St $37(B)$ for both control (open bars) and dTC treated (filled bars) muscles. Although cluster length varied 2-30 $\mu \mathrm{m}$, their distribution was nearly identical in control and activity-blocked muscles at both stages. In addition, the length distribution of receptor clusters present in muscles at the beginning of the cell death period $(A)$ was very similar to that in muscles at the end of the cell death period (B).

by a presynaptic profile along greater than half their length is doubled at both St 33 and St 36 in curare compared to control embryos, the uncorrected counts at these later stages may overestimate the difference in synapse number between control and curare-treated embryos. In fact, count corrections could be estimated by assuming a worst case scenario in which all of the control synapses are only one-half the length of the synapses in dTC-treated muscles. These calculations (described in more detail in Materials and Methods) were made for both St 31 and St 37 embryos. While the corrected counts were lower in absolute number for all conditions, the ratio of synapses in control and activity-blocked muscles was similar to that obtained using the uncorrected data ( 3.3 vs. 2.5 at $\mathrm{St} 31$ and 1.4 vs. 1.1 at $\mathrm{St}$ 37 , uncorrected vs. corrected counts respectively; see Table 1). 


\section{Table 4. The number of synaptic and nonsynaptic AChR clusters in the PITIB during normal development and following activity blockade}

\begin{tabular}{|c|c|c|c|c|c|c|c|c|c|}
\hline \multirow[b]{2}{*}{ Stage } & \multicolumn{3}{|c|}{ Synaptic AChR clusters } & \multicolumn{3}{|c|}{ Nonsynaptic AChR clusters } & \multicolumn{3}{|c|}{ Total AChR clusters } \\
\hline & Control & dTC & Ratio & Control & $\mathrm{dTC}$ & Ratio & Control & dTC & Ratio \\
\hline 28 & $132 \pm 12$ & 125 & 1.0 & $742 \pm 97$ & 492 & 0.66 & $874 \pm 141$ & 617 & 0.7 \\
\hline 29 & 279 & $440 \pm 88$ & 1.6 & 1106 & $228 \pm 54$ & 0.21 & 1385 & $668 \pm 141$ & 0.5 \\
\hline 30 & 2223 & 6913 & 3.1 & 3587 & 2127 & 0.59 & 5810 & 9040 & 1.6 \\
\hline 33 & $7725 \pm 1367$ & $17,201 \pm 2384$ & 2.2 & $9008 \pm 3249$ & $5689 \pm 840$ & 0.63 & $16,747 \pm 4600$ & $22,890 \pm 258$ & 1.4 \\
\hline 36 & 20,783 & 28,337 & 1.4 & 9337 & 2803 & 0.30 & 30,120 & 31,140 & 1.0 \\
\hline
\end{tabular}

Ratio $=\mathrm{dTC} /$ Control; $n=2-5$, mean \pm SEM, except where $n=2$.

In all experiments, the total number of $\mathrm{AChR}$ clusters, including both those colocalized and those not colocalized to a nerve profile, were quantified. As would be expected from the large number of noncolocalized receptor clusters present during the stages of development we examined, the total number of receptor clusters always exceeded the number of synapses. In Table 4 the number of noncolocalized or nonsynaptic clusters has been determined by subtracting the number of colocalized clusters from the total number of receptor clusters. For comparison, the number of synaptic clusters has also been reprinted from Table 1 .

During early stages of normal development (St 28-29), the number of nonsynaptic clusters exceeded synaptic clusters by 5-6-fold. However, from St 30-33, when most myotubes were brought into synaptic contact, the number of nonsynaptic clusters decreased from 1.6 to only 1.2 of synaptic values. Activity blockade, in contrast to its effect of increasing the number of synapses, reduced the number of nonsynaptic clusters at all developmental stages. This effect was most dramatic at St 29 when the number of noncolocalized clusters was reduced to only $20 \%$ of control values. In summary, activity blockade greatly increased the rate of synapse formation as well as the actual number of synapses formed during the motoneuron cell death period, while decreasing the number of $\mathrm{AChR}$ clusters that were not associated with a nerve profile.

\section{Discussion}

In this paper, the simultaneous labeling of the pre- and postsynaptic elements in chick thigh muscle revealed that the mature configuration of the NMJ, characterized by the tight spatial colocalization of synaptic vesicles and $\mathrm{AChR}$ clusters, is attained via the gradual restriction of synaptic vesicles and AChR clusters to regions of nerve-muscle contact. Although the presence of the nerves is required for $\mathrm{AChR}$ clusters to form on myotubes, as evidenced by the observation that essentially no AChR clusters formed on aneural myotubes in vivo, the initial formation of AChR clusters during in vivo neuromuscular development does not require direct nerve contact. These data strongly suggest that early in synaptogenesis the nerve normally induces AChR clustering via the release of a diffusible substance.

Quantitative comparisons made between synaptogenesis during normal development and following activity blockade to prevent cell death showed a large increase in the number of synapses in treated muscles. That the increase in the peak rate of synapse formation caused by activity blockade occurred prior to the onset of normal cell death suggests a crucial role for synapse formation in the regulation of motoneuron number. These results are discussed separately below and, where relevant, com- parisons are made with other species and with in vitro observations.

\section{The formation of $A C h R$ clusters}

AChR clusters appeared in developing thigh muscles at St 25 (see also Godfrey et al., 1988; Fallon and Gelfman, 1989), and though individual muscle nerves had not yet formed, the main sciatic and crural trunks were present beside the developing musclc masscs at this timc. Clustcrs did not appcar randomly within the developing muscle masses, but formed only on myotubes that were within approximately $200 \mu \mathrm{m}$ of the nerve trunks. At slightly later stages (St 29-31) when the large intramuscular nerve trunks had grown into the muscles, large numbers of non-nerve-contacted AChR clusters were observed within several hundred microns of these nerve trunks. The presence of these AChR clusters on myotubes distant from the nerves suggested several possible explanations: that there were many SV2-negative processes and therefore these seemingly noncontacted clusters were actually induced by axons we could not visualize, that these clusters were the result of transient contacts between axons and myotubes, or that they were induced by a diffusible substance emanating from the nerves. By using a variety of other markers to label the axons ( $\mathrm{C}-2$ antibody, DiI, HRP) we showed that SV2 appeared to label most, if not all, of the axons, and that there are very few axons in position to make transient contacts with the myotubes as they grow in to form the large intramuscular nerve trunks; thus neither of the first 2 possibilities is supported by our data. In addition we have shown 2 separate examples where $\mathrm{AChRs}$ form on myotubes that have never been in contact with axons: first, in muscles younger than St 27, where we know from HRP fills (Tosney and Landmesser, 1985) and C-2 antibody labeling (Dahm and Landmesser, 1988) that axons have not actually entered the muscle, but rather, are still within the large muscle nerve which sits on the muscle surface; and, second, within the region of the IFIB muscle that is next to the PITIB muscle nerve. Taken together our observations indicate that the formation of AChR clusters does not require close contact with the nerve, and suggest that the nerves are a source of a diffusible signal which can act over hundreds of microns to induce AChR clustering on nearby myotubes. Several molecules capable of inducing AChR clusters and/or increasing the number of receptors on myotubes in vitro have been described, including factors isolated from brain/spinal cord (i.e., ARIA, Usdin and Fischbach, 1986) and from basal lamina (i.e., agrin, Nitkin et al., 1987), as well as the peptide CGRP, which is present in some spinal cord motoneurons (Fontaine et al., 1986; New and Mudge, 1986; but see Peng et al., 1989). In addition, other more ubiquitous molecules can also affect $\mathrm{AChR}$ 
aggregation (ascorbic acid, Knaack and Podleski, 1985; transferrin, Markelonis and Oh, 1983). At this point it would be premature to speculate which, if any, of these molecules mediates the induction of receptor clustering described in this study.

The idea that nerves normally induce AChR clustering on myotubes in vivo was substantiated by our observation that essentially no receptor clusters formed on aneural myotubes. This is consistent with more qualitative observations made in chick hindlimb muscles (Fallon and Gelfman, 1989), but is in contrast to in vitro observations where AChR clusters are observed to form on myotubes in the absence of nerves (Fischbach and Cohen, 1973; Anderson and Cohen, 1977). This disparity may reflect a difference in the type of myotube present during initial synaptogenesis in vivo compared to that used for in vitro experiments. In vivo, only primary myotubes are present during the initial stages of AChR cluster formation, synaptogenesis and cell death, while most in vitro experiments make exclusive use of secondary myotubes which do not appear in the limb muscles until the end of the cell death period, well after the initial period of synaptogenesis. In addition, primary and secondary myotubes appear to be generated from different populations of precursor cells which migrate into the developing hindlimb at different times (Bonncr and Hauschka, 1974; Miller and Stockdale, 1986a, b). The differences between primary and secondary myotubes are also underscored by their requirements for different media in cell culture (White et al., 1975). Finally, the fact that secondary myotubes are generated after the nerves have made their initial functional contacts and are, therefore, subjected to a different environment during their differentiation than are primary myotubes may affect their capacity to cluster AChRs.

We observed 2 types of AChR clusters during development. The earliest to appear (St 25) were not localized to a nerve profile but were near the nerve trunks. As development progressed, AChR clusters began to be colocalized to nerve profiles and this process increased throughout development so that by the end of the cell death period (St 37), the majority of receptor clusters were in contact with a nerve profile. Since the noncolocalized receptor clusters present during initial synaptogenesis, although not synaptic by our definition, were clearly induced by the nerve, we do not consider them equivalent to the extra-synaptic receptors found in the adult.

The number of noncolocalized receptor clusters increased throughout development, suggesting that some receptor clustering continued to occur in response to a diffusible factor from the nerve. Two hypotheses have been proposed concerning the mechanism of nerve-induced AChR clustering, termed the "trophic factor" and the "contact and adhesion" hypotheses (reviewed by Bloch and Pumplin, 1988). The former suggests that the axons release a diffusible substance that causes the clustering of AChRs in nearby myotubes, while the latter proposes that receptor clustering occurs as a result of nerve-muscle contact and adhesion. The results of this study favor the trophic factor hypothesis, especially during early development (St 25-30). At later stages, as side branch formation increases the likclihood of direct contact between axons and myotubes, it seems probable that nerve contact could play an increasingly important role in the induction of $\mathrm{AChR}$ clustering. In fact, recent tissue culture experiments (Rodriguez-Marin and Cohen, 1988) suggest that the capacity of the shaft of an axon to induce AChR clusters is progressively lost following the formation of a stable synapse by the terminal region of that axon. Thus, the selective stabi- lization of synapses at side branches could induce the gradual loss of noncontacted receptor clusters along the nerve trunks via a similar mechanism.

It was curious that dTC suppressed the formation of noncolocalized AChR clusters while increasing the formation of colocalized, i.e., synaptic, clusters. One possibility is that simply by increasing the rate of synapse formation, dTC treatment resulted in a larger number of myotubes being contacted by the nerve with a consequent loss of noncolocalized receptor clusters from these myotubes. In vitro, nerve contact has been shown to result in the rapid dispersal of pre-existing clusters (Kuromi and Kidokoro, 1984). Another possibility is that dTC acting as a partial agonist, as it does at immature rat neuromuscular junctions (Ziskind and Dennis, 1978), could destabilize noncolocalized (nonsynaptic) clusters. Bloch (1986) has reported that carbachol results in the loss of receptor clusters both in vitro and in vivo. Nonsynaptic clusters might be preferentially affected if synaptic clusters are stabilized by other influence from the nerve acting very locally.

Finally, if $\mathrm{ACh}$ itself were inducing receptor clusters to form, dTC treatment might preferentially block this effect at nonsynaptic clusters. Being a low-affinity antagonist, dTC might be capable of blocking the effect at nonsynaptic clusters where $\mathrm{ACh}$ concentrations would be low, but not at synaptic clusters where ACh concentrations would be much higher. In addition, other locally acting neural influences might preferentially stabilize synaptic clusters, counteracting the effect of dTC. Nerve-induced receptor clusters have been shown to form even in the presence of neuromuscular blocking agents (Anderson and $\mathrm{Co}$ hen, 1977; Davey and Cohen, 1986).

\section{Synaptogenesis during normal development}

Muscle nerves contact the developing PITIB and IFIB muscles beginning at St 27 (Tosney and Landmesser, 1985; Dahm and Landmesser, 1988). AChR clusters were first observed in direct anatomical contact with nerve profiles in the developing PITIB and IFIB muscles at St 27, and the dorsal muscle mass, from which these muscles derive, was also first observed to contract in response to stimulation of spinal nerves 4,5 , and 6 (which innervate the PITIB and IFIB) at St 27 (Landmesser and Morris, 1975). Although these data are consistent with anatomically defined synapses mediating the earliest contractions, these early twitch contractions (3-5 sec) are much slower than those mediated by mature synapses. The very slow time course of these early contractions and the fact that contraction in immature avian myotubes can occur in the absence of muscle action potentials (Saito and Ozawa, 1986) is at least consistent with the possibility that some of the muscle activation is due to $\mathrm{ACh}$ diffusing to nonsynaptic clusters. This idea is supported both by our observation that more than $90 \%$ of the receptor clusters present in the muscles at St 27 were not localized to a nerve profile (although they were within $200 \mu \mathrm{m}$ of a nerve trunk), and the fact that muscles at these stages lack acetylcholinesterase (Ishikawa and Shimada, 1982). Our observations are also consistent with the idea that $\mathrm{ACh}$ (as well as other molecules) may be released along the entire length of the axons during early development rather than only from the terminal region of the axon. This idea is supported by tissue culture experiments (Chow and Poo, 1985; Sun and Poo, 1987), as well as by our observations that both SV2 antigen and vesicular profiles were initially distributed throughout the length of the growing axons. Examination of the electrophysiological and anatomical corre- 
lates of synapse formation within the same muscle would help to elucidate the mechanism of early muscle contraction.

It is clear from this study as well as others (Jacob and Lentz, 1979; Smith and Slater, 1983) that an AChR cluster is not synonymous with a synapse in developing chick muscles, neither does the early, diffuse distribution of SV2 antigen accurately predict the location of synapses. In fact, the adult configuration of the $\mathrm{NMJ}$ is achieved via the progressive restriction of both SV2 antigen and AChR clusters to discrete sites of nerve-muscle contact, as has also been recently observed in mouse diaphragm (Lupa and Hall, 1989). However, the aggregation of AChRs to form clusters is temporally correlated with the onset of functional activity in chick thigh muscle (as described above), in Xenopus myotomal muscle (Chow and Cohen, 1983), and in frog pectoralis (Linden et al., 1988) suggesting that contraction is mediated via binding of $\mathrm{ACh}$ to these clusters and further that receptor clustering may be required for muscle contraction in vivo. In contrast, in the rat intercostals (Dennis et al., 1981; Ziskind-Conhaim and Bennett, 1982) and diaphragm (Braithwaite and Harris, 1979), the onset of functional activity precedes the appearance of AChK clusters by 12-24 hr, indicating that early muscle contraction can also be mediated by receptors distributed diffusely in the myotube membranc.

The percent of colocalization of AChR clusters and nerve profiles increased throughout development in both muscles; however, at all stages the pattern of nerve branching determined the spatial distribution of AChR cluster formation (i.e., clusters always formed on myotubes near or in contact with nerves). The increase in percent colocalization was due primarily to an increase in synapse formation rather than the regression of nonnerve associated clusters, in other words, the total number of synapses increased throughout development. Although noncolocalized receptor clusters disappeared from around the main nerve trunks, others appeared near side branches, and in fact the absolute number of non-nerve-associated clusters also increased during development. Based on the results of this study, even though many noncolocalized clusters were observed around the intramuscular nerve trunks prior to the formation of side branches, it is not possible to say to what extent, if any, axons may have contacted these clusters rather than, as observed in vitro (Anderson and Cohen, 1977; Frank and Fischbach, 1979), induced new receptor clusters to form at the site of contact.

\section{The effect of activity blockade on synaptogenesis}

The normal course of synaptic development was characterized by an increase in the length of apposition between AChR clusters and presynaptic nerve profiles. At the mature NMJ, the size and shape of the pre- and postsynaptic elements are well matched. Earlier work in the chick wing (Burden, 1977a) had shown that this was due, at least in part, to a decrease in the length of clusters beginning at $\mathrm{St} 36$ (the earliest time point studied). Our results indicate that the normal course of synapse maturation (from St 30-36) also involves the growth of the nerve terminal to match the length of the cluster (see also Jacob and Lentz, 1979; Smith and Slater, 1983). Treatment with dTC resulted in an increase in the percentage of AChR clusters colocalized with a presynaptic nerve terminal along greater than half the length of the cluster (i.e., an increase in synapse length). This suggests that activity blockade increased the maturation rate of the synapses.

Activity blockade altered the rate of synapse formation so that more synapses formed at the beginning of the cell death period producing a 3-fold increase in the total number of synapses at $\mathrm{St} 30$ in activity blocked compared to normal muscles. Thus, the total number of synapses at St $\mathbf{3 0}$ in activity blocked muscles was equivalent to the number in St 33 control muscles (6913 vs. 7725 total synapses, respectively). The fact that a treatment which prevents motoneuron cell death produced a large change in the rate of synapse formation prior to the onset of normal cell death strongly suggests that synapse formation plays a critical role in regulating motoneuron survival. This hypothesis could be directly tested by counting the number of synapses and motoneurons under conditions which perturb synapse formation. Consistent with our findings are observations that activity blockade results in an increase in the number of endlates/myotube in older (day 16-21) embryos (Gordon et al., 1974; Ding et al., 1983; Oppenheim and Chu-Wang, 1983; Oppenheim et al., 1989).

The results of a previous paper suggested that side branches are the sites of trophic uptake in muscles and that regulation of their numbers controls the number of surviving motoneurons (Dahm and Landmesser, 1988). Since synapse formation and side branch formation are correlated, it is likely that the regulation of branching also controls the number of synapses formed. Since the extent of branching in the IFIB can be altered by interfering with the function of different cell adhesion molecules (Landmesser et al., 1988), quantification of synapses in such treated muscles will directly test the idea that the extent of nerve branching determines the number of synaptic sites. It will also be interesting to try to block synapse formation without perturbing nerve branching. If this is possible, one could then determine if the formation of side branches alone is sufficient to allow motoneurons to survive or if synapse formation is an absolute requirement. This will shed light on the type of nervemuscle contact required for successful trophic interactions.

\section{References}

Abercrombie M (1946) Estimation of nuclear population from microtome sections. Anat Rec 94:274-329.

Anderson MJ, Cohen MW (1977) Nerve-induced and spontaneous redistribution of acetylcholine receptors on cultured muscle cells. $\mathrm{J}$ Physiol 268:757-773.

Anderson MJ, Fambrough DM (1983) Aggregates of acetylcholine receptors are associated with plaques of basal lamina heparan sulfate proteoglycan on the surface of skeletal muscle fibers. J Cell Biol 97: 1396-1411.

Bevan S, Steinbach JH (1977) The distribution of $\alpha$-bungarotoxin binding sites on mammalian skeletal muscle developing in vivo. J Physiol (Lond) 267:195-213.

Bloch RJ (1986) Loss of ACh receptor clusters induced by treatment of cultured rat myotubes with carbachol. J Neurosci 6:691-700.

Bloch RJ, Pumplin DW (1988) Molecular events in synaptogenesis: nerve-muscle adhesion and postsynaptic differentiation. Am J Physiol 254:C345-C364.

Bonner PH, Hauschka SD (1974) Clonal analysis of vertebrate myogenesis. Dev Biol 37:317-328.

Braithwaite AW, Harris AJ (1979) Neural influence on acetylcholine receptor clusters in embryonic development of skeletal muscle. Nature 279:549-551.

Buchanan J, Sun Y-A, Poo M-M (1989) Studies of nerve-muscle interactions in Xenopus cell culture: fine structure of early functional contacts. J Neurosci 9:1540-1554.

Buckley K, Kelly R (1985) Identification of a transmembrane glycoprotein specific for secretory vesicles of neuronal and endocrine cells. J Cell Biol 100:1284-1294.

Burden S (1977a) Acetylcholine receptors at the developing neuromuscular junction: developmental change in receptor turnover. Dev Biol 61:79-85.

Burden S (1977b) Development of the neuromuscular junction in the 
chick embryo: the number, distribution, and stability of acetylcholine receptors. Dev Biol 57:317-329.

Chow I, Cohen MW (1983) Developmental changes in the distribution of acetylcholine receptors in the myotomes of Xenopus laevis. J Physiol 339:553-571.

Chow I, Poo M-M (1985) The release of acetylcholine from embryonic neurons upon contact with muscle cell. J Neurosci 5:1076-1082.

Cunningham TJ (1982) Naturally occurring neuron death and its regulation by developing neural pathways. Int Rev Cytol 74:163-186.

Dahm LM, Landmesser LT (1988) The regulation of intramuscular nerve branching during normal development and following activity blockade. Dev Biol 130:621-644.

Davey DF, Cohen MW (1986) Localization of ACh receptors and cholinesterase on nerve-contacted and noncontacted muscle cells grown in the presence of agents that block action potentials. J Neurosci 6: 673-680.

Dennis MJ (1981) Development of the neuromuscular junction: inductive interactions between cells. Ann Rev Neurosci 4:43-68.

Dennis MJ, Ziskind-Conhaim L, Harris AJ (1981) Development of neuromuscular junctions in rat embryos. Dev Biol 81:266-279.

Ding R, Jansen JK, Laing NG, Tonnesen H (1983) The innervation of skeletal muscle in chickens curarized during early development. J Neurocytol 12:887-919.

Fallon JH, Gelfman CE (1989) Agrin-related molecules are concentrated at acetylcholine receptor clusters in normal and aneural developing muscle. J Cell Biol 108:1527-1535.

Fischbach GD, Cohen SA (1973) The distribution of acetylcholine sensitivity over uninnervated and innervated muscle fibres grown in cell culture. Dev Biol 31:147-162.

Fontaine B, Klarsfeld A, Hokfelt T, Changeux J-P (1986) Calcitonin gene-related peptide, a peptide present in spinal cord motoneurons, increases the number of acetylcholine receptors in primary cultures of chick embryo myotubes. Neurosci Lett 71:59-65.

Frank E, Fischbach GD (1977) Early events in neuromuscular junction formation in vitro. Induction of acetylcholine receptor clusters in the postsynaptic membrane and morphology of newly formed nervemuscle synapses. J Cell Biol 83:143-158.

Fredette BJ, Landmesser LT (1990) A re-evaluation of the role of innervation in primary and secondary myogenesis in developing chick muscle. Dev Biol 143 (in press).

Ginsborg BL, Mackay B (1961) A histochemical demonstration of two types of motor innervation in avian skeletal muscle. Bibl Anat 2:174 181.

Godfrey EW, Siebenlist RE, Wallskog PA, Walters LM, Bolender DL, Yorde DE (1988) Basal lamina components are concentrated in premuscle masses and at early acetylcholine receptor clusters in chick embryo hindlimb muscles. Dev Biol 130:471-486.

Gordon T, Tuffery AR, Vrbová G (1974) Possible mechanisms determining synapse formation in developing skeletal muscles of the chick. Cell Tissue Res 155:13-25.

Hamburger V, Hamilton HL (1951) A series of normal stages in the development of the chick embryo. J Morphol 88:49-82.

Hamburger V, Oppenheim R (1982) Naturally occurring cell death in vertebrates. Neurosci Comment 7:39-55.

Hollyday M (1983) Development of motor innervation of chick limbs. Limb Development and Regeneration. New York: Liss.

Honig M, Hume R (1986) Fluorescent carbocyanine dyes allow living neurons of identified origin to be studied in long-term cultures. J Cell Biol 103:71-187.

Ishikawa Y, Shimada Y (1982) Acetylcholine receptors and acetylcholinesterase in developing chick skeletal muscle fibers. Dev Brain Res 5:187-197.

Jacob M, Lentz TL (1979) Localization of acetylcholine receptors by means of horseradish peroxidase- $\alpha$-bungarotoxin during formation and development of the neuromuscular junction in the chick. J Cell Biol 82:195-211.

Knaack D, Podleski T (1985) Ascorbic acid mediates acetylcholine receptor increase induced by brain extract on myogenic cells. Proc Natl Acad Sci USA 82:575-579.

Kuromi H, Kidokoro Y (1984) Nerve disperses pre-existing ACh receptor clusters prior to induction of receptor accumulation in Xenopus muscle cultures. Dev Biol 103:53-61.

Lamb AH (1984) Motoneuron death in the embryo. Crit Rev Clin Neurobiol 1:141-179.
Lance-Jones C, Landmesser L (1981) Pathway selection by chick lumbosacral motoneurons during normal development. Proc R Soc London [B] 214:1-18.

Landmesser L (1978) The development of motor projection patterns in the chick hindlimb. J Physiol (Lond) 284:391-414.

Landmesser L, Morris D (1975) The development of functional innervation in the hind limb of the chick embryo. J Physiol (Lond) 249: 301-326.

Landmesser L, Honig M (1986) Altered sensory projections in the chick hindlimb following early removal of motoneurons. Dev Biol 118:511-531.

Landmesser L, Dahm L, Schultz K, Rutishauser U (1988) Distinct roles of adhesion molecules during innervation of embryonic chick muscle. Dev Biol 130:645-670.

Letinsky MS, Morrison-Graham K (1980) Structure of developing frog neuromuscular junctions. J Neurocytol 9:321-342.

Linden DC, Jerian SM, Letinsky MS (1988) Neuromuscular junction development in the cutaneous pectoris muscle of Rana catesbiana. Exp Neurol 99:735-760.

Linden DC, Letinsky MS (1988) Correlated muscle and nerve development in the bullfrog cutaneous pectoris. Exp Neurol 99:709-734.

Lupa MT, Hall ZW (1989) Progressive restriction of synaptic vesicle protein to the nerve terminal during development of the neuromuscular junction. J Neurosci 9:3937-3945.

Markelonis GJ, Oh TH (1983) Sciatin is a transferrin from sciatic nerve with myotropic activity upon cultured muscle. J Neurochem 41(Suppl):S108B.

McLennan IS (1983) The development of the pattern of innervation in chicken hindlimb muscles: evidence for specification of nervemuscle connections. Dev Biol 97:229-238.

Miller JB, Stockdale FE (1986a) Developmental origins of skeletal muscle fibers: clonal analysis of myogenic cell lineages based on fast and slow myosin heavy chain expression. Proc Natl Acad Sci USA 83:3860-3864

Miller JB, Stockdale FE (1986b) Developmental regulation of the multiple myogenic cell lineages of the avian embryo. I Cell Biol 103: 2197-2208.

Nakajima Y, Kidokoro Y, Klier FG (1980) The development of functional neuromuscular junctions in vitro: an ultrastructural and physiological study. Dev Biol 77:52-72.

New HV, Mudge AW (1986) Calcitonin gene-related peptide regulates muscle acetylcholine receptor synthesis. Nature 323:809-811.

Nitkin RM, Smith MA, Magill CX, Fallon JR, Yao Y-M, Wallace BG, McMahan UJ (1987) Identification of agrin, a synaptic organising molecule from Torpedo Electric Organ. J Cell Biol 105:2471-2478.

Oppenheim R (1975) The role of supraspinal input in embryonic motility: a re-examination in the chick. J Comp Neurol 160:37-50.

Oppenheim RW, Chu-Wang I-W (1983) Aspects of motoneuron cell death in the chick spinal cord during embryonic development. In: Somatic and autonomic nerve-muscle interactions (Bumstock $G$, O'Brien R, Vrbova G, eds), pp 57-107. Amsterdam: Elsevier.

Oppenheim RW, Bursztajn S, Prevette D (1989) Cell death of motoneurons in the chick embryo spinal cord: XI. Acetylcholine receptors and synaptogenesis in skeletal muscle following the reduction of motoneuron death by neuromuscular blockade. Development 107 : 331-341.

Peng HB, Bridgeman PS, Nakajima S, Greenberg A, Nakajima Y (1979) A fast development of presynaptic function and structure of the neuromuscular junction in Xenopus tissue culture. Brain Res 167:379384.

Peng HB, Chen Q, De Biasi S, Zhu D (1989) Development of calcitonon gene-related peptide (CGRP) immunoreactivity in relationship to the formation of neuromuscular junctions in Xenopus myotomal muscle. J Comp Neurol 290:533-543.

Phillips WD, Lai K, Bennett MR (1985) Spatial distribution and size of acetylcholine receptor clusters determined by motor nerves in developing chick muscles. J Neurocytol 14:309-325.

Pilar GR, Meriney SD, Gray DB (1988) Trophic effects of muscle on nerve cell survival and development. Nerve-Muscle Cell Trophic Communication. Boca Raton: CRC Press; chap 9, 173-198.

Pittman R, Oppenheim RW (1978) Neuromuscular blockade increases motoneuron survival during normal cell death in the chick embryo. Nature 271:364-366.

Pittman R, Oppenheim RW (1979) Cell death of motoneurons in the 
chick embryo spinal cord. IV. Evidence that a functional neuromuscular interaction is involved in the regulation of naturally occurring cell death and the stabilization of synapses. J Comp Neurol 187:425446.

Rodriguez-Marin E, Cohen MW (1988) The capacity of non-growthcone portions of neurites to trigger the development of a postsynaptic specialization. J Neurosci Abstr 14:515.

Saito K, Ozawa E (1986) Contraction of cultured chick myotubes induced by electrical stimulation. Biomed Res 7:69-77.

Schuetze SM, Role LW (1987) Developmental regulation of nicotinic acetylcholine receptors. Ann Rev Neurosci 10:403-457.

Smith MA, Slater CR (1983) Spatial distribution of acetylcholine receptors at developing chick neuromuscular junctions. J Neurocytol 12:993-1005.

Steinbach JH (1981) Developmental changes in acetylcholine receptor aggregates at rat skeletal neuromuscular junctions. Dev Biol 84:267276.

Sun Y, Poo M-M (1987) Evoked release of acetylcholine from the growing embryonic neuron. Proc Natl Acad Sci USA 84:2540-2544.

Takahashi T, Nakajima Y, Hirosawa K, Nakajima S, Onodera K (1987) Structure and physiology of developing neuromuscular synapses in culture. J Neurosci 7:473-481.

Tanaka H, Landmesser L (1986) Cell death of lumbosacral motoneurons in chick, quail, and chick-quail chimeras: a test of the quantitative matching hypothesis of neuronal cell death. J Neurosci 6:28892899.
Tosney K, Landmesser L (1985) Specificity of early motoneuron growth cone outgrowth in the chick hindlimb. J Neurosci 5:2336-2344.

Tzartos SJ, Lindstrom JM (1980) Monoclonal antibodies used to probe acetylcholine receptor structure: localization of the main immunogenic region and detection of similarities between subunits. Proc Natl Acad Sci USA 77:755-759.

Usdin TB, Fischbach GD (1986) Purification and characterization of a polypeptide from chick brain that promotes the accumulation of acetylcholine receptors in chick myotubes. J Cell Biol 103:493-507.

Vogel M, Landmesser L (1987) Distribution of fiber types in embryonic chick limb muscles innervated by foreign motoneurons. Dev Biol 119:481-495.

Weldon PR, Cohen MW (1979) Development of synaptic ultrastructure at neuromuscular contacts in an amphibian cell culture system. J Neurocytol 8:239-259.

While NK, Bonner PH, Nelson DR, Havshka SD (1975) Clonal analysis of vertebrate myogenesis of colony-forming cells. Dev Biol 44: 346-361.

Ziskind L, Dennis MJ (1978) Depolarizing effect of curare on embryonic rat muscles. Nature 276:622-623.

Ziskind-Conhaim L, Bennett JI (1982) The effects of electrical inactivity and denervation on the distribution of acetylcholine receptors in developing rat muscle. Dev Biol 90:185-197. 